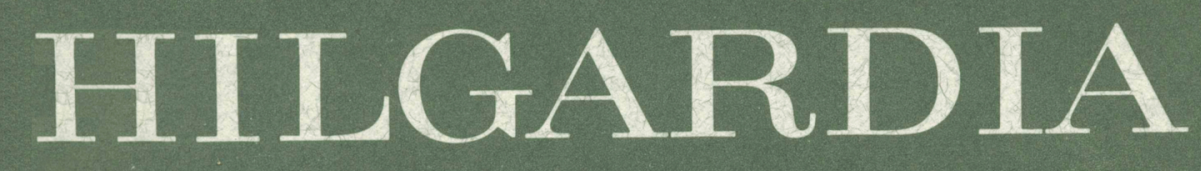

A JOURNAL OF AGRICULTURAL SCIENCE PUBLISHED BY THE CALIFORNIA AGRICULTURAL EXPERIMENT STATION

Volume 38, Number $16 \cdot$ November, 1967

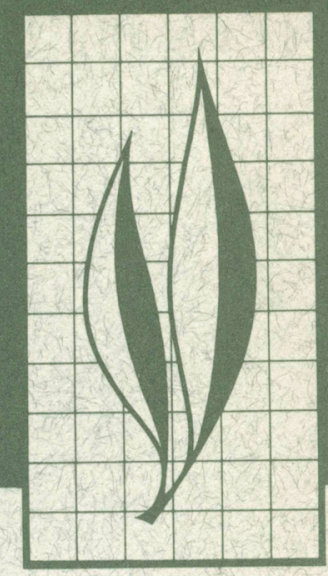

\title{
Biological Control of Prickly Pear Cacti on Santa Cruz Island, California
}

Richard D. Goeden, Charles A. Fleschner, and Donald $W$. Ricker 


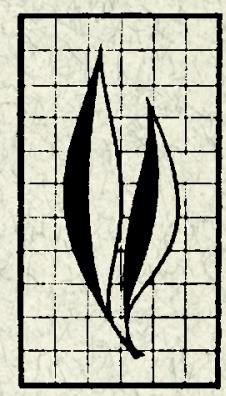

This publication summarizes 25 years of heretofore unreported efforts to effect the biological control of prickly pear cacti infesting rangeland on Santa Cruz Island, situated off the coast of southern California. To date, partial to substantial biological control of the pest cacti, Opuntia littoralis (Engelmann) Cockerell, $O$. oricola Philbrick, and their hybrids, has been achieved. The principal biological control agent is a cochineal insect, Dactylopius sp., which is native to the southern California mainland. It was introduced to the island free of its principal natural enemies-Hyperaspis taeniata significanis Casey and Latilia coccidivora (Comstock) - and has multiplied markedly, at the same time destroying numerous clumps of cacti throughout the island.

Effective range management practices, i.e., eradication of wild sheep and restrained cattle grazing, have aided the biological control efforts, and both have resulted in the return and persistence of annual grasses on formerly overgrazed and cacti-infested grazing lands.

The coreid bugs, Chelinidea tabulata (Burmeister) and C. vittiger Uhler, were also successfully introduced to Santa Cruz Island from Texas and mainland California, respectively, but neither species is thought significant as a biological control agent. The cactus-feeding phycitids, Olycella junctolineella (Hulst), Melitara dentata (Grote), and M. prodenialis Walker, were not successfully colonized on Santa Cruz Island.

\section{THE AUTHORS:}

Richard D. Goeden is Lecturer in Biological Control, and Assistant Entomologist in the Experiment Station, Riverside.

Charles A. Fleschner is Professor of Biological Control, and Entomologist in the Experiment Station, Riverside.

Donald W. Ricker is Laboratory Technician IV, Department of Biological Control, Riverside. 


\section{Biological Control of Prickly Pear Cacti on Santa Cruz Island, California ${ }^{1,2}$}

\section{INTRODUCTION}

Santa Cruz Island lies 25 miles south of Santa Barbara and 60 miles west of Los Angeles, off the coast of southern California. The island is 24 miles long and ranges in width from 2 to $61 / 2$ miles. It is the largest and most rugged of the four Santa Barbara Channel Islands, and is the only one in the group that is divided longitudinally by a central valley (fig. 1). The valley, which follows a fault line, lies between a steep-sloped north ridge, which rises to over 2,400 feet, and a more eroded south ridge, which varies from 1,000 to 1,200 feet in elevation. Most of the island lies below 2,000 feet elevation (fig. 2). Steep slopes and sharp ridges characterize the terrain, and steep cliffs, the coastline. Wide beaches and wave-cut marine terraces are found, however, at the southern and western ends of the island. The geology of Santa Cruz Island was described in detail by Bremner (1932).

The climate of Santa Cruz Island apparently has not been studied (personal communication, P. C. Orr, Santa Barbara Museum of Natural History). Definitely Mediterranean in character, however, it undoubtedly compares favorably with that of the adjacent coastal mainland, which is characterized by limited diurnal and seasonal temperature fluctuations, rainless summers, and usually frost-free winters. At equivalent latitude and longitude, coastal summer temperatures average $65^{\circ}$ to $70^{\circ} \mathrm{F}$, and the annual rainfall, 15 to 20 inches (Stone, 1964).

Distribution of the native tree and shrub cover as of 1943 is shown in figure 3 . The remainder of the island was largely given over to grassland and prickly pear cacti (fig. 4).

The Stanton Ranch, with headquarters in the central valley (fig. 2), occupies approximately 55,000 acres of the western portion of the island. Cattle were grazed on Santa Cruz as early as 1865 , and were reintroduced following purchase of the island by Edwin L. Stanton in 1937 (Hillinger, 1958). The previous owners' chief source of income was from the sale of sheep-a domestic species which had gone wild, overrun the island, and overgrazed its grasslands. These sheep were thought to have been introduced initially by early Spanish colonists (Hillinger, 1958). Sheep and cattle thus subsequently competed for forage.

Sheep eradication and restricted cattle grazing carried out by the Stanton Ranch have significantly aided biological control efforts by reducing overgraz-

\footnotetext{
${ }^{1}$ Submitted for publication November 3, 1966.

2 This paper resulted from studies now associated with Agricultural Experiment Station Project H-2002, Biological Control of Noxious Weeds Infesting Agricultural, Recreational, Residential, and Industrial Areas in California.
} 


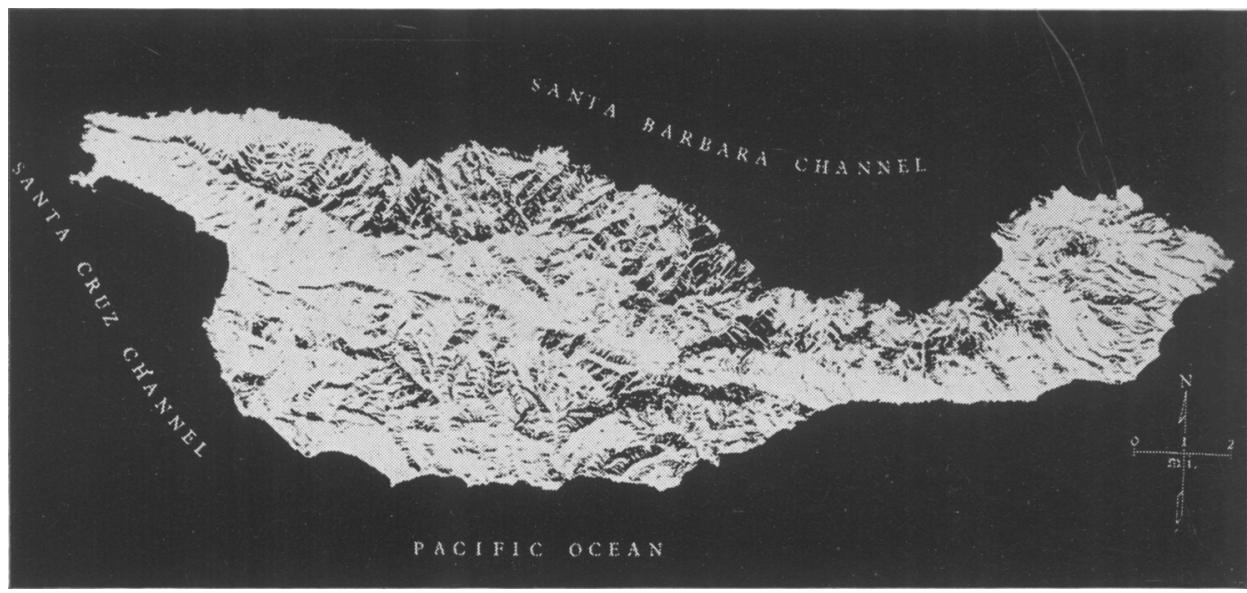

Fig. 1. Aerial relief map of Santa Cruz Island, Santa Barbara County, California. (Modified from Bremner (1932) by permission of Santa Barbara Museum of Natural History.)

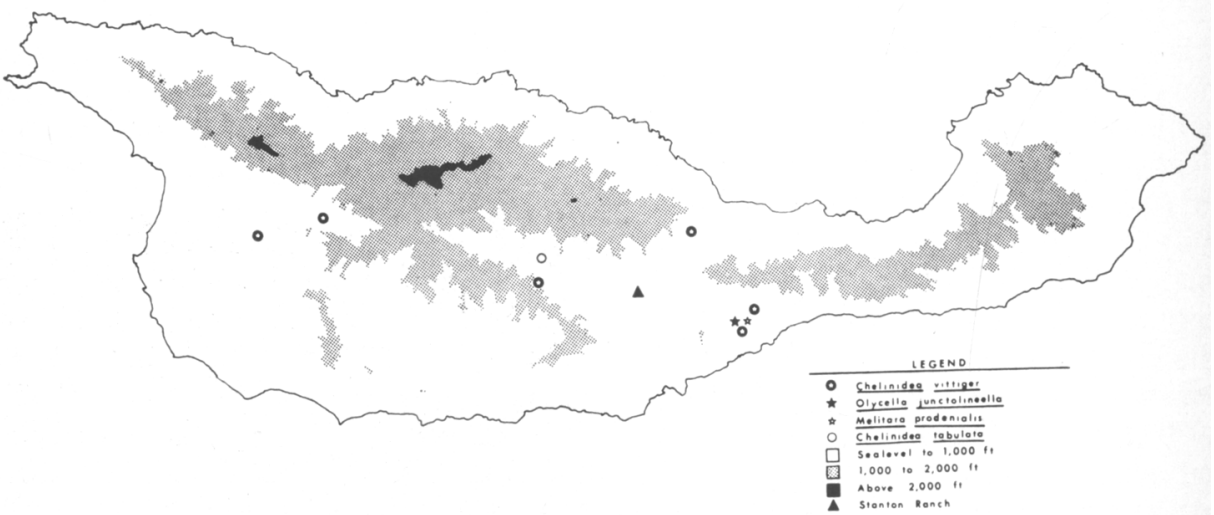

Fig. 2. Elevations and 1961 to 1964 cactus-insect release sites on Santa Cruz Island.

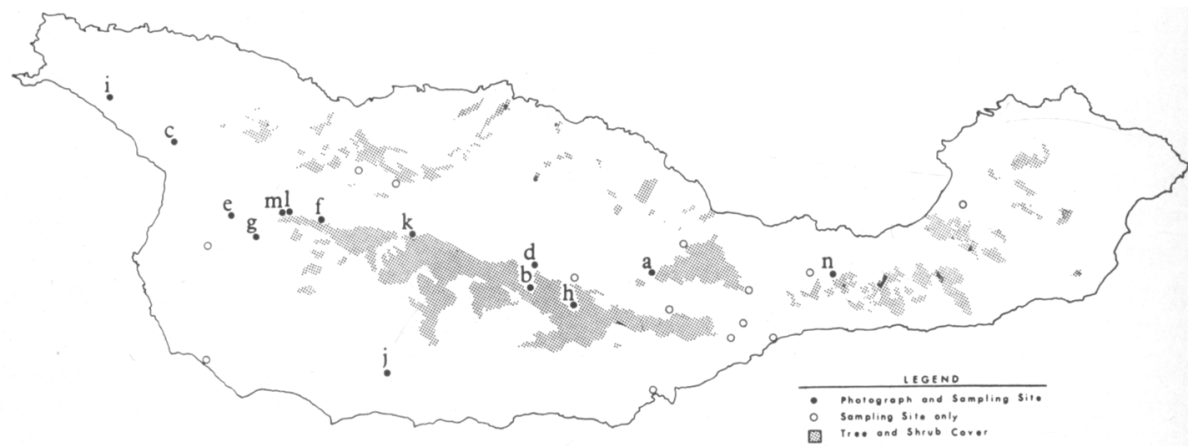

Fig. 3. Distribution of native tree and shrub cover, also sampling and/or photographic sites on Santa Cruz Island. The alphabetized site designations reflect the sequence in which these sites were established during the period 1961 to 1965 . 
ing, thus promoting stronger competition between the cacti and resident range grasses. During the past decade, the island has been laced with many miles of stout, woven and barbed-wire fencing. The thousands of wild sheep trapped within the enclosures thus formed were at first sold commercially, but in recent years they have simply been systematically shot. Approxi- mately 4,000 sheep were trapped in 1957 alone (Hillinger, 1958).

Other continuing range management efforts include an attempt to eradicate the wild boars, which were also introduced to the island by early Spanish settlers (Hillinger, 1958). These animals root under or rip through the fencing and thus allow trapped sheep to escape.

\section{THE PROBLEM}

Two species of coastal prickly pear infest Santa Cruz Island: Opuntia littoralis (Engelmann) Cockerell $(=O$. occidentalis var. littoralis (Engelmann) Parish) and $O$. oricola Philbrick. Both species are common to coastal southern California, including the Channel Islands, from Santa Barbara County southward (Munz and Keck, 1959; Philbrick, 1964). On Santa Cruz Island, $O$. littoralis $\times O$. oricola hybrids are common, and apparently well outnumber either parent species (Philbrick, personal communication). Infestations vary from scattered, compact clumps, on the better grasslands of the central valleys and on the narrow neck of the island, to dense, nearly unbroken stands that cover many of the southfacing slopes of the north and south ridges (fig. 4). In the past, severe overgrazing by wild sheep greatly facilitated the spread of these cacti. On grasslands denuded by sheep, cactus pads broken from clumps came into immediate contact with the soil, took root; and established many new clumps.

In 1938, during a visit to Riverside, California, A. J. Nicholson, the noted Australian ecologist, interested $\mathrm{Mr}$. Stanton, the owner of Santa Cruz Island, in the Australian program of biological control of prickly pear cacti. (See Dodd, 1940, for a comprehensive review of this program.) Stanton estimated that approximately 40 per cent of the rangeland of Santa Cruz was rendered useless by dense infestations of prickly pear. Shortly thereafter, he asked Harry S. Smith, of the Department of Biological Control, Riverside, to introduce the cactus moth, Cactoblastis cactorum (Berg), from Australia, where it had been so instrumental in prickly pear control (Dodd, 1940). Professor Smith attempted to discourage Stanton's interest in $C$. cactorum, because the moths probably would have reached the mainland once they had colonized on

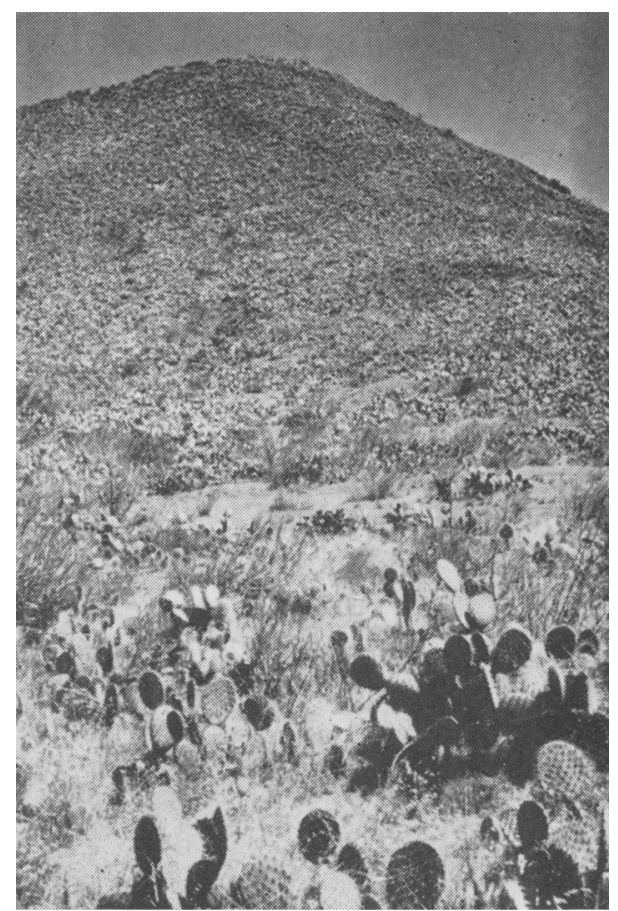

Fig. 4. Severe infestation of prickly pear cacti on a south-facing slope at the western end of Santa Cruz Island, 1961. 
Santa Cruz Island. Since prickly pear cacti were used as emergency forage during times of drought by some southwestern ranches, and the fruit and pads of several species of Opuntia were used as food in Mexico and, to a small extent, in the United States (Hunter, Pratt, and Mitchell, 1912; Johnston and Tryon, 1914), objections would have been raised to possible wholesale destruction of the plants by the moths. After visiting the island in 1939, Smith instead offered to introduce native, cactus-feeding insects to Santa Cruz to attempt biological control. Despite this offer, and attempts to realize it, Stanton continued, unsuccessfully, through 1958, to press for the introduction of $C$. cactorum. However, neither federal nor state permission to import this species was granted.

The present study summarizes 25 years of previously unreported efforts to effect biological control of prickly pear cacti on Santa Cruz Island. The work described is, in several respects, unique in the history of the biological control of weeds. Two men (both now deceased) who were the earliest exponents of biological weed control in North America participated directly in these investigations. They were Harry S. Smith, mentioned above, and James $K$. Holloway, former leader for Biological Control of Weeds Investigations, U. S. Department of Agriculture, Agricultural Research Service. Furthermore, the earliest introductions of cactus-feeding insects from the mainland to Santa Cruz Island by Smith antedated by several years the spectacularly successful introduction of Chrysolina spp. to California for the control of Klamath weed, Hypericum perforatum Linnaeus (Smith, 1947; Holloway and Huffaker, 1949), generally considered to be the first attempt at entomological weed control in North America. Finally, because of the objections to introduction of $C$. cactorum, and because of the unique insular location of the infestation, this likely will remain the only large-scale attempt at the biological control of prickly pear cacti undertaken in this country.

Many of the early data have been derived from correspondence files and insectary records of the Department of Biological Control, Riverside, and from correspondence made available to the authors by various individuals and agencies.

\section{BIOLOGICAL CONTROL OF PRICKLY PEAR CACTI ${ }^{3}$}

\section{Resident Cactus Insects}

A limited number of phytophagous insect species were associated with cacti on Santa Cruz before the biological control efforts began. Over the years, the principal ones have been identified. $\mathrm{Ob}$ viously, they, like their cactus hosts, had managed to bridge the Channel barrier an undetermined number of years ago.

Asphondylia opuntiae Felt (Diptera: Cecidomyiidae), a fruit-infesting spe- cies of widespread occurrence throughout the prickly pear areas of the western United States and northern Mexico (Dodd, 1940), was the only cactus-feeding insect noted by Smith during his initial visits to Santa Cruz Island. The larvae feed within, disfigure, and eventually destroy the immature fruit. Several American and Australian investigators considered this species a limiting

${ }^{3}$ Credits for determination of some of the insects mentioned in this section are as follows: Narnia inornata by J. L. Herring; Ozamia fuscomaculella by W. D. Duckworth; Marmara opuntiella by D. R. Davis; Volucella marginata, $\nabla$. lutzi, $\nabla$. mexicana, $V$. nigra, and $\nabla$. tau by W. W. Wirth. All persons listed are with the U. S. National Museum, Entomology Research Division, Agricultural Research Service, U. S. Department of Agriculture, Washington, D. C. 
factor in the reproduction of prickly pear by seed (Hunter, Pratt, and Mitchell, 1912; Johnston and Tryon, 1914).

Narnia inornata Distant (HemipteraHeteroptera: Coreidae), collected by the authors in recent years on the island, evidently belonged to the resident fauna. Smith never noted its presence, and there is no record of its introduction to the island. Hunter, Pratt, and Mitchell (1912) reported its occurrence in California. Even when abundant, this fruit-feeding species inflicts little visible damage; therefore, Hunter, Pratt, and Mitchell (1912), Johnston and Tryon (1914), and Dodd (1940) agreed that $N$. inornata was of little significance as a natural enemy of Opuntia spp.

Ozamia fuscomaculella (Wright) (Lepidoptera: Phycitidae) were reared from fruit collected on Santa Cruz. Each solitary larva of this species destroys several fruit during the course of its development (Hunter, Pratt, and Mitchell, 1912; Dodd, 1940).

Field observations indicated that $A$. opuntiae, N. inornata, and O. fuscomaculella are of little importance as biological control agents on Santa Cruz Island.

Marmara opuntiella Busck (Lepidoptera: Gracillariidae) occasionally was detected mining the subepidermal tis- sues of cactus pads on the island; however, its numbers were few and its larvae caused only negligible damage. Described by Hunter, Pratt, and Mitchell (1912) as being widespread in Texas, this species evidently is also resident in California.

The cactus scale, Diaspis echinocacti (Bouché) (Hemiptera-Homoptera: Coccidae), was first detected on Santa Cruz by Harold Compere, of the Department of Biological Control, Riverside, in 1939 (personal communication). Although this insect was relatively common, evidence of damage was slight, and we believe that this species plays a very limited role as a natural enemy of cacti on the island.

Several Syrphidae commonly breed in deteriorating Opuntia on Santa Cruz: Volucella (Copestylum) marginata Say; V. lutzi Curran; V. mexicana Macquart; V. nigra Greene; and V. tau Bigot. The first of these scavengers was reported from Los Angeles and Riverside by Hunter, Pratt, and Mitchell (1912). Volucella spp. apparently are associated with decaying cacti throughout North and South America (Dodd, 1940). They aggravate injuries caused by primary phytophagous species, and bring about a more rapid deterioration of infested prickly pear (Johnston and Tryon, 1914).

\section{Cactus Insects Introduced for Biological Control ${ }^{4}$}

Biological control of the prickly pear cacti on Santa Cruz Island was thought possible if the resident cactus insects could be supplemented with additional species introduced from the mainland free of their own natural enemies. Australian researchers had subjected many native cactus-infesting species to exhaustive feeding tests to insure their safe introduction to Australia for

\footnotetext{
${ }^{4}$ Credits for determination of some of the organisms mentioned in this section are as follows: Chelinidea tabulata by R. C. Froeschner, U. S. National Museum, Entomology Research Division, Agricultural Research Service, U. S. Department of Agriculture, Washington, D. C.; Beauveria bassiana by I. M. Hall, Department of Biological Control, Riverside; Olycella junctolineella by H. W. Capps, U. S. National Museum; Sympherobius barberi, by P. A. Adams, California State College, Fullerton, and O. S. Flint, U. S. National Museum; S. bifasciatus by O. S. Flint; Eremochrysa punctinervis by P. A. Adams; Leucopis n. sp. by J. F. McAlpine, Canadian Department of Agriculture, Ottawa, Ontario; Aegilips sp. (possibly clarimontis) and Pachyneuron mucronatum by B. D. Burks, U. S. National Museum; P. eros by P. H. Timberlake, Department of Biological Control, Riverside.
} 
prickly pear control (Alexander, 1925; Dodd, 1940). In 1940, Smith received permission from the U. S. Department of Agriculture and the California Department of Agriculture to collect and transport to California, from the various prickly pear areas in the United States, a number of phytophagous insects that were restricted in their feeding habits mainly to the genus Opuntia of the Cactaceae. Following that permission, living Chelinidea spp., Dactylopius spp., Melitara spp., and Olycella junctolineella Hulst were introduced for the biological control of prickly pear cacti on Santa Cruz Island.

No life history studies were conducted on the island because of its isolated location. In the discussion that follows, each species is introduced by a summary of the life history taken from the literature.

\section{Chelinidea tabulata (Burmeister)}

Chelinidea tabulata (HemipteraHeteroptera: Coreidae) (fig. 5) is primarily a Mexican species which ranges northward into lower Texas (Hamlin, 1924). Hunter, Pratt, and Mitchell (1912) considered this and other Chelinidea spp. to be the "... principal insects injurious to Opuntia." Hamlin (1924) described all stages and offered a limited account of its biology.

Eggs in groups of two to 12 are affixed linearly to the underside of cactus spines. Incubation lasts from nine to 13 days, and nvmphal development approximately 58 days (Hamlin, 1924). From two (Alexander, 1925) to five (Hamlin, 1924) generations occur annually. Both nymphs and adults feed on the sap of many species of prickly pear. Feeding injury is indicated by localized chlorotic lesions which coalesce under sufficiently severe attack, and lead to a general yellowing and structural weakening of plants, accompanied by pad abscission and sometimes death.

Collection and colonization. Smith first collected $C$. tabulata at Uvalde,

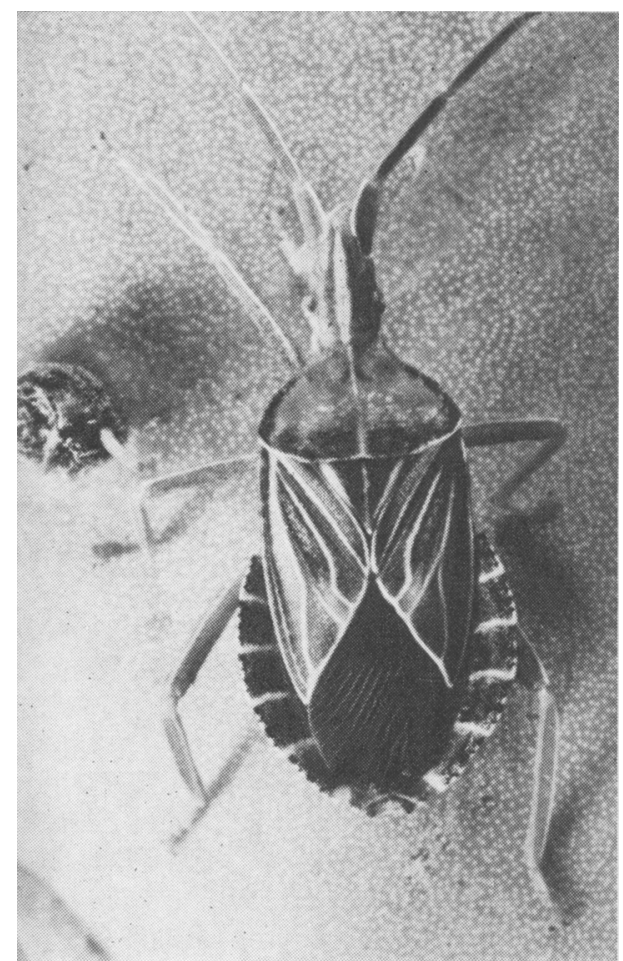

Fig. 5. Adult Chelinidea tabulata.

Texas, on August 10, 1945. He shipped approximately 50 adults to Riverside, in a Wardian cage, by Railway Express. Upon arrival on August 15, the specimens were transferred to a cage with freshly-cut prickly pear pads, and were held for rearing in the insectary. These specimens and all subsequent shipments of cactus-feeding insects collected by Smith were processed in quarantine, and reared in the insectary by Harold Compere. Later in August, Smith took another collection to Riverside by car from Brownsville, Texas. On September 11, 1945, a few reared nymphs were released on Santa Cruz. Smith remarked in a letter dated February 5, 1949, that he thought $C$. tabulata had not been established on Santa Cruz, and he apparently made no additional releases of this species.

On June 8 and 9, 1961, 485 C. tabulata were collected by D. W. Ricker at Norias, Texas. This shipment arrived 
at the quarantine facility on June 12, and 250 live adults were recovered. Approximately 1,400 nymphs were reared in the insectary by July 13 on locally collected $O$. occidentalis Engelmann and Bigelow.

Five hundred of these fourth- and fifth-instar nymphs were transported to Santa Cruz Island on August 15, 1961. Before this 500-nymph consignment was released, several nymphs of C. tabulata were discovered in a canyon 2 miles east of the ranch headquarters (fig. 2). Subsequent search of the immediate area yielded considerable numbers of both nymphs and adults. This probably had been a site for Smith's attempted colonization of $C$. tabulata in 1945. Further search for this species in the central valley of the island proved fruitless, and the 500 nymphs were released 2.2 miles west of the ranch headquarters on August 17 (fig. 2).

Results. We currently consider $C$. tabulata to be of little value as a biological control agent. Although introduced to the island in 1945, this species apparently has spread and multiplied but little during the ensuing years, and has caused little detectable damage to the prickly pear. During a survey of the phytophagous insect fauna at selected sample sites (fig. 3) on May 13 to 16 , 1966, C. tabulata was detected at several isolated points, but generally its numbers were few and its colonies were restricted in area. Its semisedentary habit may partially account for its restricted spread on the island. Alexander (1925) reported that the adults showed little propensity for flight. Dodd (1940) termed the adults "sluggish" and found C. tabulata unable to compete with Cactoblastis cactorum, in Australia, because the bugs would starve rather than migrate to uninfested prickly pear once their food supply was destroyed by $C$. cactorum.

\section{Chelinidea vittiger Uhler}

Chelinidea vittiger (fig. 6) is widely distributed throughout the cactus area of the United States from the Atlantic to the Pacific coasts and northern Mexico (Dodd, 1940). Hunter, Pratt, and Mitchell (1912) described all stages of the insect and briefly discussed its biology.

From three to 16 eggs per mass are affixed linearly to the undersurface of cactus spines. Incubation lasts 12 to 20 days, and nymphal development 41 to 42 days (Hunter, Pratt, and Mitchell, 1912; Hamlin, 1924). Two generations are produced annually (Alexander, 1925). The adults overwinter in the debris beneath cactus clumps. Both nymphs and adults feed gregariously on pads of Opuntia spp. Feeding damage is similar to that described for C. tabulata.

Collection and colonization. As early as 1939, Smith mentioned rearing a mainland-occurring Chelinidea (undoubtedly $C$. vittiger) for release on Santa Cruz. However, these specimens apparently never were introduced to the island. On August 10, 1945, Smith collected "a few hundred nymphs and adults" at Uvalde, Texas. These specimens arrived, via Railway Express, at the Riverside quarantine facility on

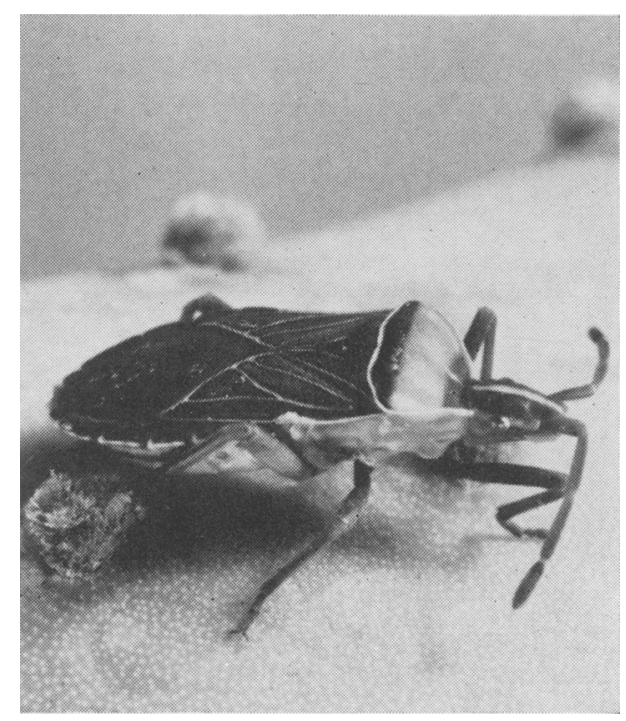

Fig. 6. Adult Chelinidea vittiger. 


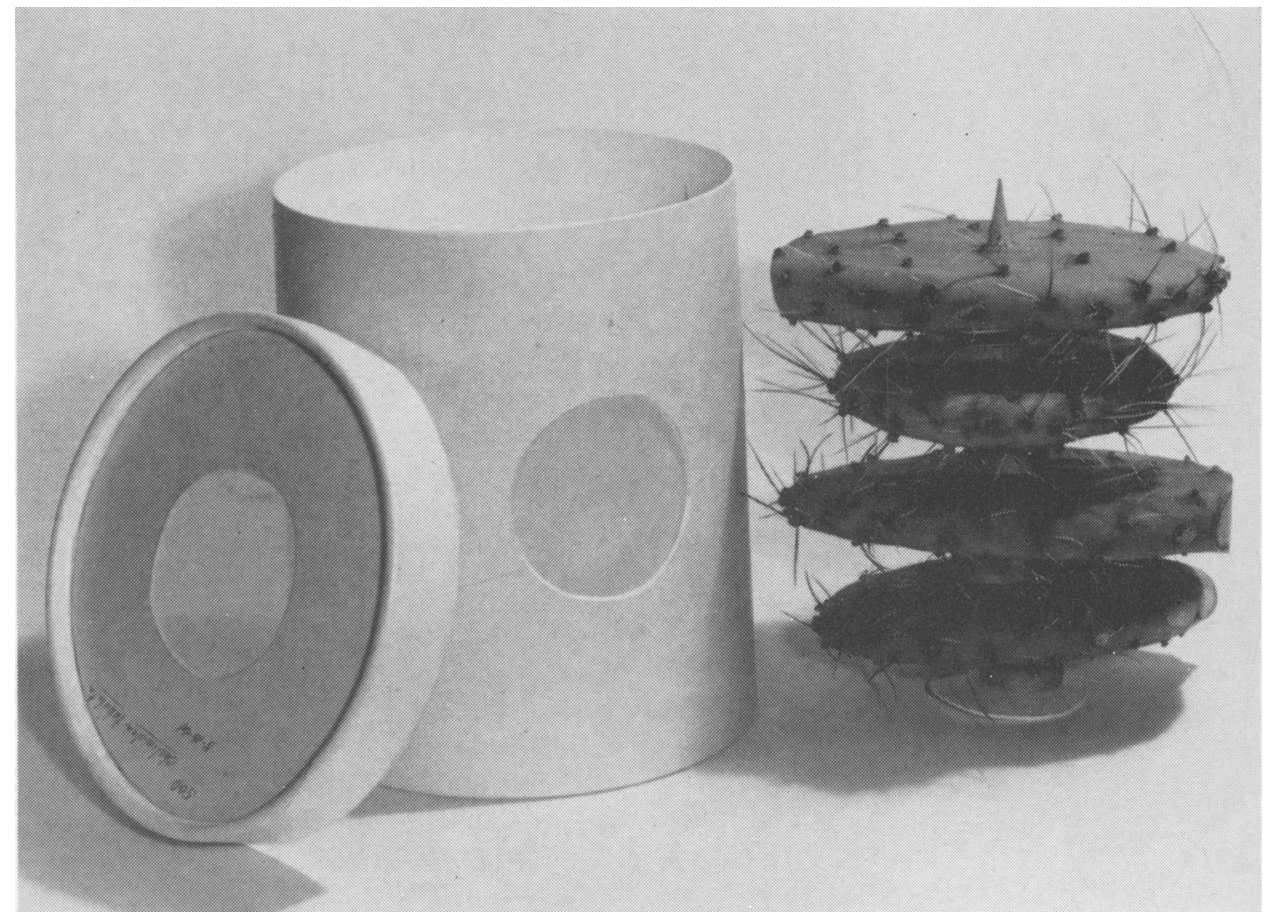

Fig. 7. Method used to transport Chelinidea spp. Cactus pads alternating with cardboard separators were skewered on a pointed wooden dowel, and placed in a 1-gallon carton.

August 15, 1945. They immediately were transferred to pads of freshly-cut local prickly pear and were held for rearing in the insectary. On September 11,1945 , reared nymphs were liberated on Santa Cruz Island. Apparently this colonization attempt failed, for no mention subsequently was made of this species until March 2, 1959, when Holloway, after visiting the island in 1958 and 1959, puzzled over the absence of C. vittiger, and suggested that it be reintroduced from the southern California mainland.

During February and March, 1961, numerous first- through third-instar nymphs of $C$. vittiger were collected from $O$. occidentalis on the University of California campus at Riverside. These nymphs were reared in the insectary to the fourth and fifth instars. On April 18, 1961, 8,000 late-instar nymphs and 350 adults were transported to the island in 1-gallon card- board cartons filled with pads of 0 . occidentalis (fig. 7 ). These specimens were released on April 18 and 20, 1961. Four hundred, 1,800, and 3,700 adults were similarly colonized on August 7, 1961, August 14 to 15, 1962, and June 3, 1964, respectively (fig. 2). On June 3, 600 fifth-instar nymphs were also liberated.

Results. As with C. tabulata, the authors currently consider $C$. vittiger to be of little value as a biological control agent. The May 13 to 16,1966 , survey (fig. 3) indicated that $C$. vittiger was established at but two locations, both original release sites. At release sites where the prickly pear had been killed by Dactylopius sp., no $C$. vittiger could be found, nor had they spread to adjacent living clumps.

\section{Melitara spp.}

Two species of Melitara (Lepidoptera: Phycitidae) were collected for use as biological control agents: $\boldsymbol{M}$. 
dentata (Grote) and $M$. prodenialis Walker. M. dentata is distributed from Kansas to Texas and westward to Utah and New Mexico; $M$. prodenialis ranges from Oklahoma to Texas and eastward to Florida and New York (Heinrich, 1939). The biology of $\boldsymbol{M}$. dentata was described by Bugbee and Reigel (1945), that of $M$. prodenialis by Hamlin (1925).

Eggs of Melitara spp. are laid (from three to 100) in elongate, stalked masses, termed "sticks," which are attached to cactus spines (Dodd, 1940). Young larvae feed gregariously within pads, but appreciably disperse as they mature, migrate to, and infest a succession of pads (Bugbee and Reigel, 1945). $M$. prodenialis has two to three generations annually; $M$. dentata produces only one brood per year (Dodd, 1940). Plant symptoms of Melitara feeding initially include chlorosis and swelling of the infested pads, which become webbed with silk and littered with frass, followed by the decay and desiccation of excavated pads.

Collection and colonization. The initial collection of Melitara was made near Ness City, Kansas, by S. H. Eckley and W. O. Ridgway, on November 18 to 27, 1942. Six hundred pads, each infested with an estimated 10 to 50 thirdand fourth-instar larvae of $M$. dentata, were collected and shipped to Riverside. On April 26, 1942, Smith recorded that all specimens were unfortunately lost as the results of an unspecified disease.

A shipment of $M$. dentata cocoons collected by M. C. Kramer at Ness City, Kansas, on August 20, 1943, arrived at Riverside on September 3. This shipment was followed by a second consignment of cocoons on September 6, 1943. Several adults which subsequently emerged from these cocoons were caged out-of-doors at Riverside on clumps of O. occidentalis. As Smith made no further reference to these specimens, it is assumed that they died before they could be introduced to Santa Cruz.
Smith and Ernest Mortenson collected Opuntia pads infested with $M$. prodenialis near Carrizo Springs, Texas, in early 1945. Four Wardian cages filled with these pads were sent to Riverside via Railway Express. They arrived on August 17. Two additional Wardian cages containing $M$. prodenialis-infested pads collected by Smith at Palacios, Texas, arrived at Riverside on August 20. Smith also sent 29 cocoons of $M$. prodenialis on August 10 and 61 on August 15, from Carrizo Springs. Both parcels arrived at Riverside, by first-class mail, on August 20. During his return trip, Smith collected $M$. prodenialis larvae 20 miles east of Douglas, Arizona, on August 29. Infested pads and cocoons were caged in the insectary. Egg sticks laid by adults that emerged from the cocoons were collected daily. On September 11, 1945, 19 egg sticks were transported to Santa Cruz and were attached (method not recorded) to healthy cactus pads in an attempt to establish this species. No additional collections or releases of Me? itara spp. were recorded by Smith.

On June 13, 1961, three pads infested with $M$. prodenialis larvae were collected near La Pryor, Texas, and were carried by car to Riverside. Seventy larvae were dissected from these pads and were separated into small lots. Each lot was eaged on pads of local $O$. occidentalis in the insectary. By September 28, 46 cocoons were recovered. These subsequently yielded 40 adults. Only three egg sticks, containing a total of 87 eggs, were laid by these adults. The 32 larvae that hatched died shortly thereafter.

Sixty-eight $M$. prodenialis colonies, which contained an estimated total of 1,500 larvae, were collected near Aguilares, Texas, on June 4, 1962. The infested pads were carried by car to Riverside. The colonies were decimated by Beauveria bassiana (Balsamo) Vuillemin, and only 22 larvae were reared to the adult stage. These adults were shortlived, and only seven specimens sur- 


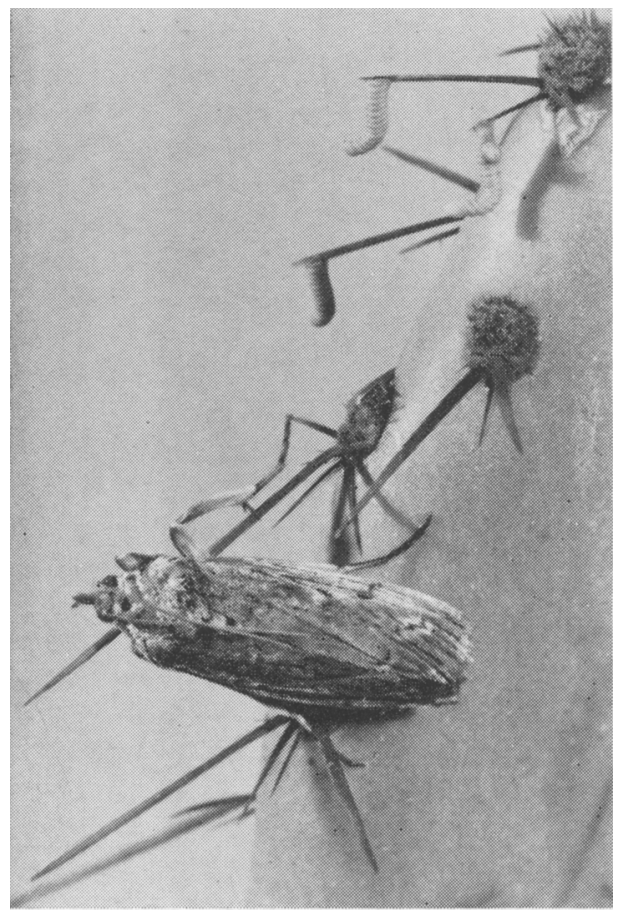

Fig. 8. Adult Olycella junctolineella, and three egg sticks laid on spines of Opuntia occidentalis in the insectary.

vived to be released on Santa Cruz on September 10, 1962 (fig. 2).

Results. Neither $M$. dentata nor $M$. prodenialis was established on Santa Cruz Island.

\section{Olycella junctolineella (Hulst)}

Olycella junctolineella (Lepidoptera: Phycitidae) (figs. 8 and 9) is native to Texas and Mexico. Adults were described by Heinrich (1939); other stages, and the biology, by Hamlin (1925).

Eggs are laid in sticks of 25 to 50 , attached to cactus spines (fig. 8). The eggs hatch in five to 12 days. Larval development lasts 10 to 12 weeks in summer and five and one-half months in winter (Hamlin, 1925). There are two generations annually. Masses of young larvae attack the pads upon which they hatch. The larvae disperse as they mature, however, and rarely is more than one later instar larva found within each infested pad. Symptoms of larval feeding include chlorosis and swelling of infested pads, but unlike those damaged by Melitara spp., these pads are not webbed externally with silken strands, and the frass is not ejected, but remains within the excavations. Mature larvae cut exit holes, drop to the ground, and pupate in the litter. Exit holes provide portals of entry for rot-inciting microorganisms and insect scavengers, such as Volucella spp.

Collection and colonization. Prickly pear pads infested with $O$. junctolineella larvae were first collected in the Laguna Atascosa National Wildlife Refuge north of Brownsville, Texas, on June 6,1961 . The pads were air-mailed to Riverside on June 7 and arrived on June 8. Twenty-six larvae that had

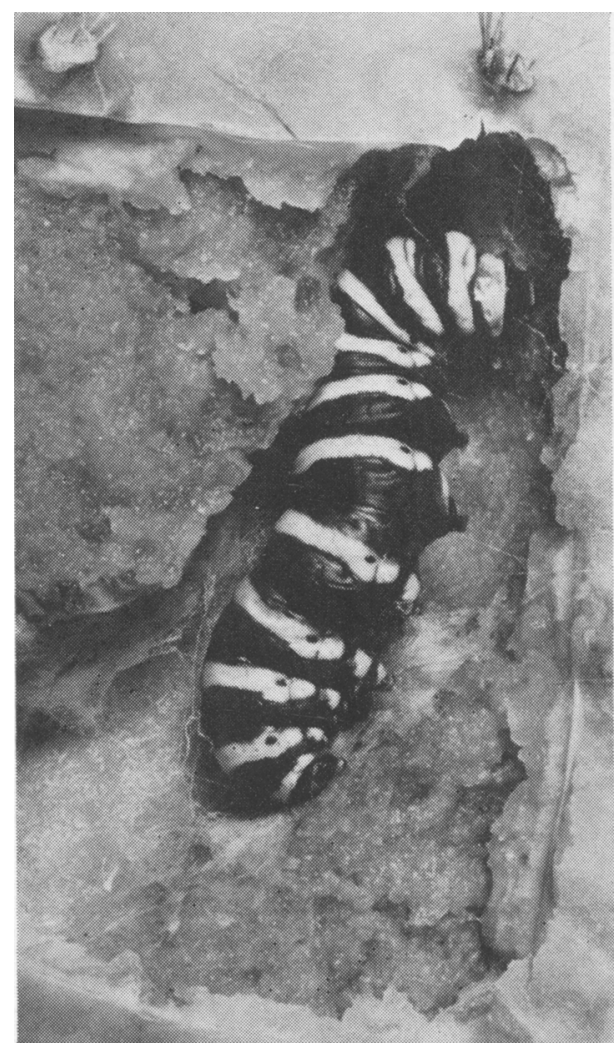

Fig. 9. Opuntia sp. pad cut open to expose a full-grown larva of Olycella junctolineella. 
emerged en route were caged with freshly-cut Opuntia occidentalis pads in the quarantine facility. The remaining infested pads in this collection also were held in quarantine.

All told, 18 larvae reached the adult stage, and laid approximately 1,200 eggs. A few egg sticks were laid on the cactus spines (fig. 8) but most were attached to the cloth or wooden walls of the sleeve cages in which the adults were held. Larvae that hatched from these eggs were caged in groups of 25 , on freshly-cut pads of $O$. occidentalis. Fresh pads were added periodically, and damaged pads were removed as larval development progressed.

Approximately 350 second- to thirdinstar larvae were released on Santa Cruz on August 17, 1961 (fig. 2). Larvae were transported to the island in 1-gallon cartons filled with freshly-cut pads. Larvae that had not entered pads, or had vacated them en route, were individually transferred to pads of healthy cactus clumps. Two open cartons filled with infested pads were placed among the pads of a healthy clump of cactus.

A second collection of approximately 100 O. junctolineella-infested pads was made 3 miles north of La Pryor, Texas, on June 13, 1961. The pads were packed in cardboard boxes, which were sealed, placed in ice chests, and taken to Riverside by car. These pads were placed in sleeve cages in the quarantine facility. A total of 82 larvae was recovered, and approximately 30 were reared to the adult stage.

The adults were caged on $O$ puntia occidentalis pads. By September 20, they had laid approximately 1,800 eggs, which were placed in $1 / 2$-gallon cartons with cactus pads. When invaded by the newly-hatched larvae, the pads were transferred to individual sleeve cages, each of which contained several freshlycut pads. Pads consumed by the developing larvae were replaced periodically by freshly-cut pads.

On November 17, 1961, 312 second- to third-instar larvae were colonized on Santa Cruz. Larvae were transported to the island in 1/2-pint cartons filled with cubes of $\boldsymbol{O}$. occidentalis pads cut to a size too small to allow the larvae to bury themselves completely. Each carton contained 25 larvae.

A new method of release was employed. A 3-inch-deep hole was cut into the edge of an intact Opuntia pad in the field, by means of a $1 / 4$-inch diameter cork borer. The plug of pad tissues was removed, and a small funnel was inserted into the hole. The larva was placed in the funnel with a forceps, and guided into the hole. The hole then was plugged with a 00 -size cork. Two days after this treatment, several pads were cut open. All larvae were found to be alive and feeding.

Several collections of $O$. junctolineella-infested pads were made in Texas between May 17 and June 12, 1962. Approximately 300, 170, 100, and 100 larvae were collected at Catarina, Aguilares, Carrizo Springs, and La Pryor, respectively. These pads were air-mailed to Riverside.

The larvae were handled in quarantine as in 1961. Disease greatly decimated these collections, and only six specimens reached the adult stage. No O. junctolineella from the 1962 collections were released on Santa Cruz.

Results. By November, 1961, the clumps on which larvae had been released on August 17 showed several collapsed branches; however, no larvae were found by dissection.

Forty pads into which larvae had been inserted on November 14, 1961, were cut open in March, 1962. No living larvae were found. Although most dissected pads showed considerable damage from internal feeding, no evidence of the extension of this feeding to adjacent pads was detected. No exit holes were found. Most excavations were filled with a viscous fluid which contained the remains of Olycella larvae.

These observations, an absence of 
fresh injury, and lack of either immature or mature $O$. junctolineella during 1963 to 1966, led us to conclude that this species had not been successfully colonized on Santa Cruz Island.

\section{Dactylopius spp.}

Several species of cochineal insects, Dactylopius spp. (Hemiptera-Homoptera: Dactylopiidae), were involved in these studies. Dactylopius spp. are associated with prickly pear cacti throughout most areas in the Americas to which the plants are native. Taxonomy of the insects is in doubt, and surprisingly little is known of their biologies. The following generalized account was taken largely from Dodd (1940).

A few hundred eggs are laid beneath the body of each female, which dies shortly after its egg complement is expended. The tiny, actively motile, firstinstar nymphs or "crawlers" hatch within hours. The crawlers are dispersed chiefly by air currents. Once the female crawler settles and inserts its proboscis, it remains stationary for life. Its legs and antennae atrophy during subsequent molts, and it becomes essentially saccate. Adult females are covered with a white, waxy, flocculent or granular secretion (plate 2). The male nymphs, on the other hand, remain motile. When mature, these nymphs spin cylindrical cocoons in which they transform to winged, adult males. Dactylopius spp. produce several broods per year. The presence of massed colonies of cochineal insects presages chlorosis, pad abscission, subsequent necrosis, and ultimate collapse of heavily attacked prickly pear clumps (plate 2).

Identity of Dactylopius sp. colonized on Santa Cruz Island. The cochineal insects successfully introduced to Santa Cruz Island in 1951 (see p. 595) presumably are descendants of specimens of the so-called "Mexican strain" of D. opuntiae Cockerell introduced to Australia for prickly pear control. The most re- cent revision of the genus Dactylopius (Ferris, 1955) unfortunately failed to treat $D$. opuntiae, even though this species figures so prominently in the accounts of the Australian prickly pear campaign (Dodd, 1940; Wilson, 1960). For this reason, we have conservatively designated the cochineal insect that was colonized on Santa Cruz Island as "Dactylopius sp." The taxonomy of this genus currently is being investigated by D. R. Miller, under the direction of $\mathrm{H}$. L. McKenzie, at the University of California, Davis, and a specific determination is deferred until such time as Miller's study is published.

Miller (personal communication) recently assured us that the Dactylopius established on Santa Cruz Island is morphologically identical with specimens that we collected in the coastal and intermediate valleys of lower southern California. He also indicated that specimens are known from Hawaii (see p. 595) and Mexico.

We believe that the cochineal insects liberated on Santa Cruz Island stemmed from specimens collected by Australians in Mexico in 1927. This colonization culminated a series of introductions from Mexico to Australia to Hawaii, and finally to Riverside and Santa Cruz Island, that spanned more than two decades. Interestingly, the natural range of this Mexican species apparently extends northward to Temecula, California, which lies but 40 miles south of Riverside.

We may trace the course of these introductions in the literature. From 1920 to 1932 the Commonwealth Prickly Pear Board of Australia imported what they termed four "strains" of $D$. opuntiae from the United States and Mexico: A "Chico strain," collected at Chico, California; an "Arizona strain," from Tucson; a "Texas strain," and a "Mexican strain," from various locations in Texas and Mexico, respectively (Dodd, 1940; Wilson, 1960). The Chico, Arizona, and Texas strains failed to attack the pest 

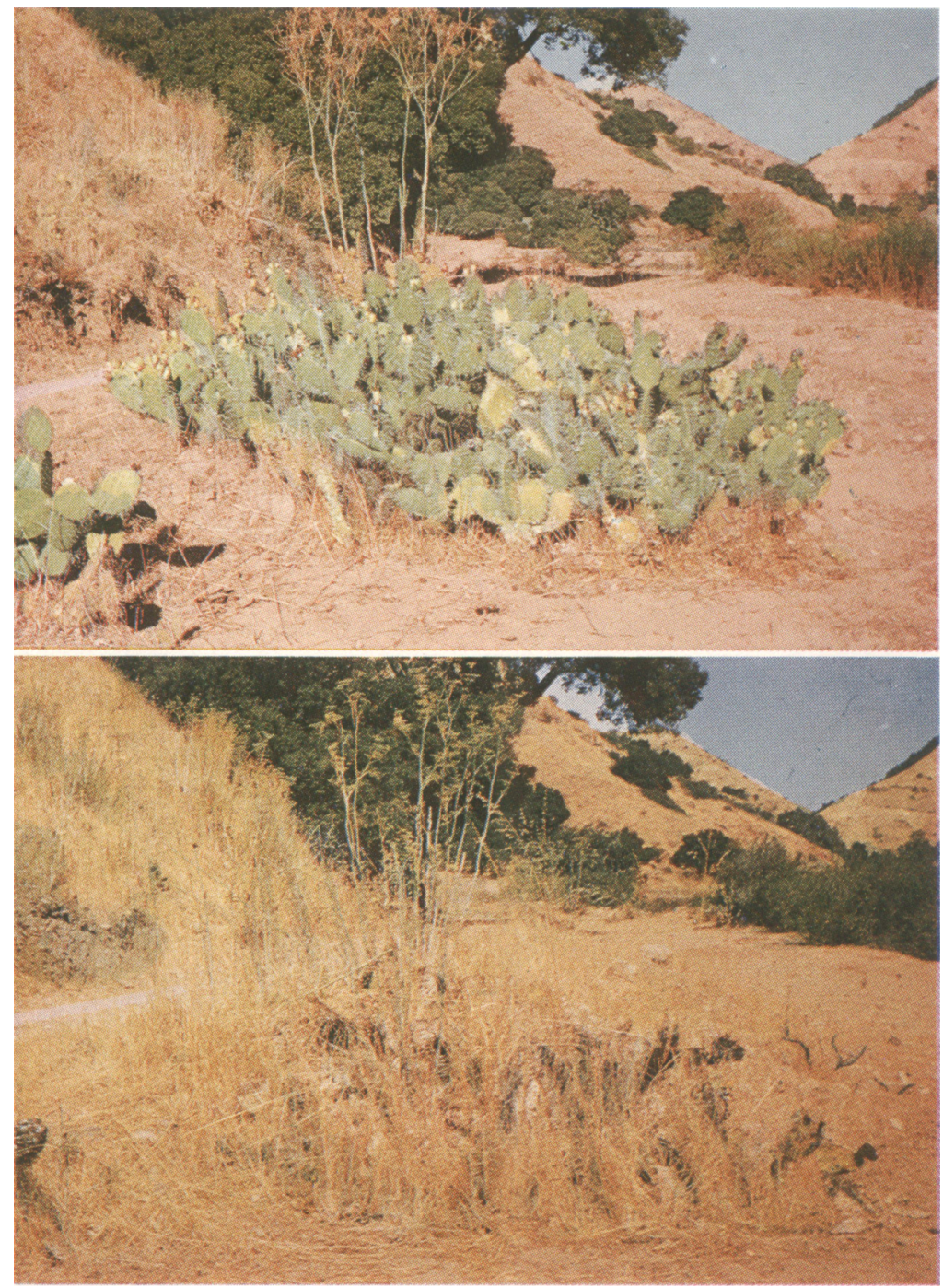

Plate 1. Top: Unidentified Opuntia sp. (probably near littoralis) on Santa Cruz Island, Site A, October, 28, 1963. Bottom: same site on October 1, 1965, showing result of Dactylopius feeding. 

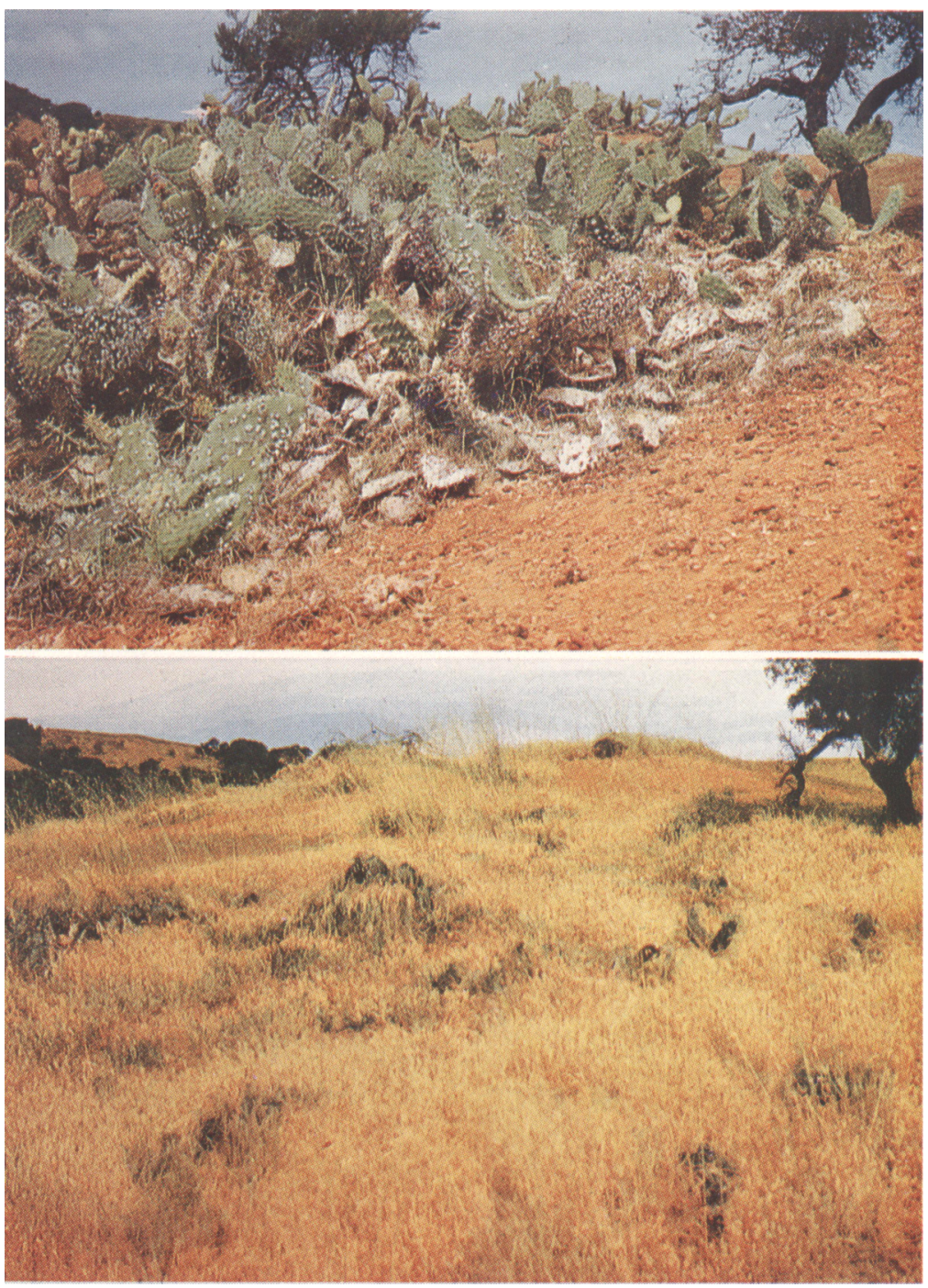

Plate 2. Top: Opuntia littoralis $\times$ O. oricola on Santa Cruz Island, Site B, April 18, 1961. Bottom: same site on May 26, 1965, showing result of Dactylopius feeding. 

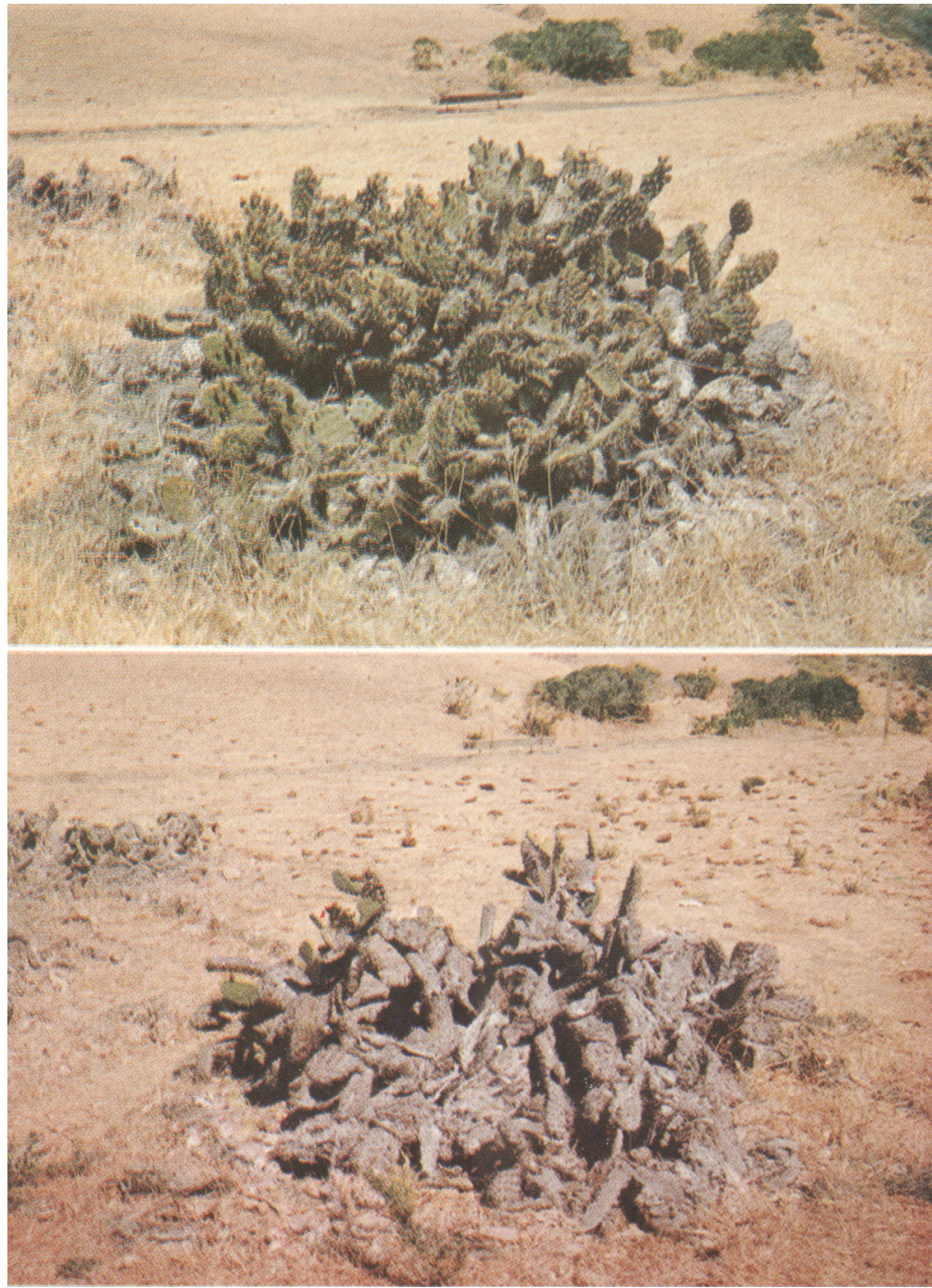

Plate 3. Top: Opuntia littoralis on Santa Cruz Island, Site F, June 3, 1964. Bottom: same site on September 29, 1965, showing result of Dactylopius feeding. 

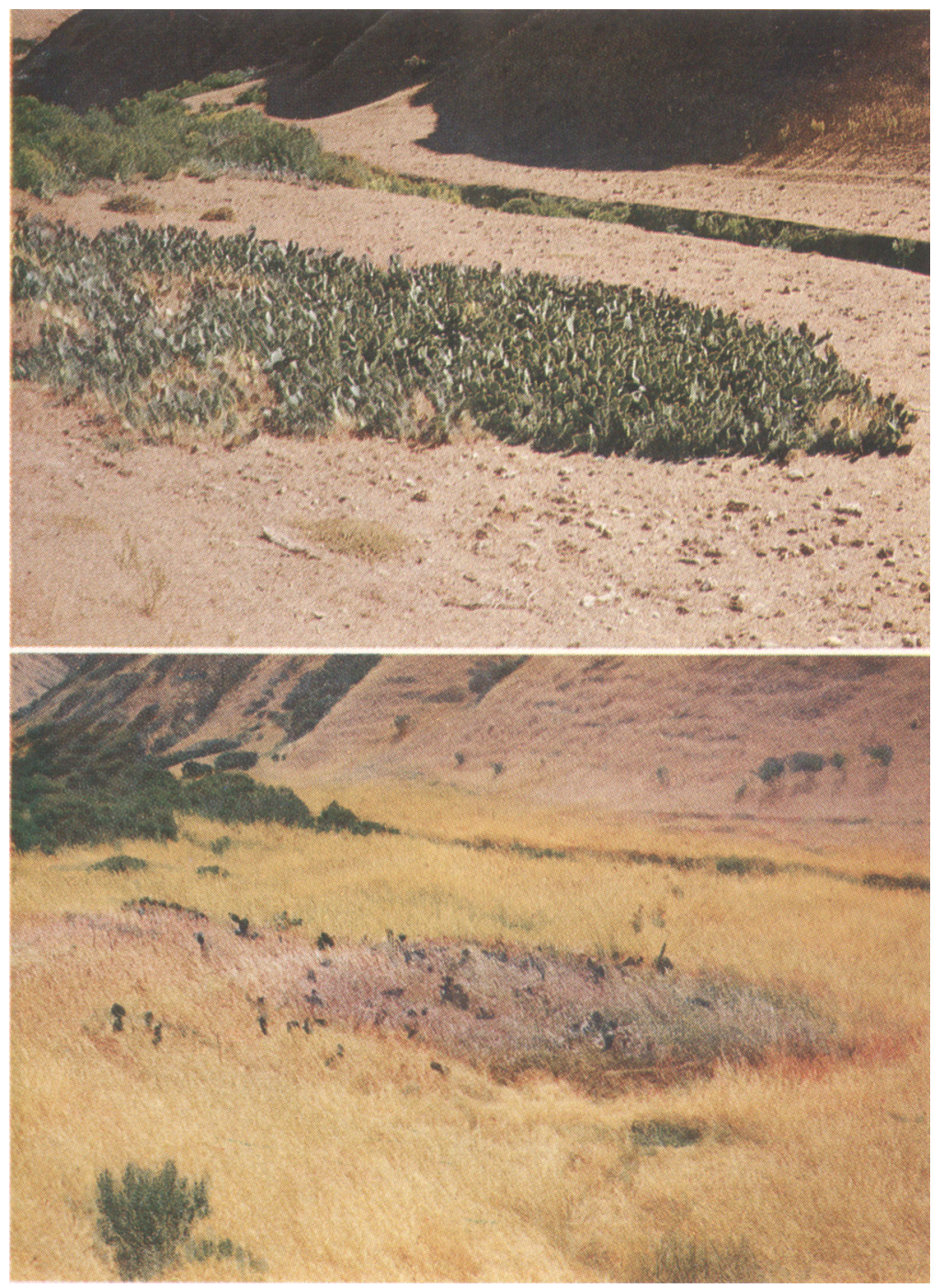

Plate 4. Top: Opuntia littoralis $\times$ O. oricola on Santa Cruz Island, Site G, October 21, 1964. Bottom: same site on May 14, 1966, showing result of Dactylopius feeding. 
pear, O. streptacantha Lamarck (Dodd, 1940). In June, 1927, however, Australian workers introduced $D$. opuntiae on o. streptacantha from Mexico. They liberated this "Mexican strain" in 1928, and subsequently reported that it readily attacked the naturalized $O$. streptacantha (Dodd, 1940). Brookes (in Wilson, 1960), subsequently recorded what probably was the Mexican strain of $D$. opuntiae from $O$. megacantha Salm-Reifferscheid-Dyck in South Australia.

Ten pads of $O$. streptacantha ". . . heavily infested with Mexican cochineal ..." were shipped to Hawaii from Australia in June, 1949, and the insects were established in Hawaii for the biological control of $O$. megacantha (Fullaway, 1954). Their return to North America from Hawaii is described below.

The cochineal insects which currently provide a measure of biological control of $\boldsymbol{O}$. oricola and $\boldsymbol{O}$. littoralis on Santa Cruz Island are therefore native to the California mainland. While their colonization on Santa Cruz terminated a series of introductions that spanned the Pacific Ocean, their natural distribution, in fact, carries them less than 120 miles southeast of the island.

Collection and colonization. The first species of cochineal insect collected, cultured, and subsequently released on Santa Cruz Island was identified by Smith as D. tomentosus (Lamarck). Specimens were first collected late in the summer of 1939 at an unspecified location in southern California. A pure culture was obtained in quarantine by isolating crawlers from these field locations.

Smith's first visit to Santa Cruz in mid-A pril, 1940, also marked his first attempt to establish Dactylopius on the island. Two additional colonizations were attempted during 1940 , but none of these efforts apparently was successful. During late May, Stanton sprinkled D. tomentosus crawlers supplied by Smith onto cactus pads. Later, in mid-
August, Smith carried infested pads to the island during the time of crawler hatch and transferred a few crawlers to each pad of a muslin-covered clump located near the ranch headquarters. (fig. 2) .

Smith collected several Opuntia pads infested with what he identified as $D$. confusus Cockerell, during late July, 1941, near Prescott, Arizona. Cultures subsequently were established under quarantine in the insectary. On June 17, 1942, Stanton transported an unspecified number of $D$. confusus-infested pads to the island. Several infested pads apiece were placed within an unspecified number of cactus clumps in the canyon that lies due north of the ranch headquarters (fig. 2) and that drains the central valley watershed. Smith subsequently noted that these incipient colonies were washed into the ocean during the following winter, which was characterized by extremely heavy rainfall.

During 1946 to 1951, Smith visited Hawaii annually. In 1950, he collected and shipped to Riverside an unspecified number of Dactylopius-infested pads of $O$. megacantha. This shipment arrived on July 28, 1950, and a culture was established on pads of local Opuntia occidentalis under quarantine in the insectary.

On May 2, 1951, approximately seven large pads heavily infested with progeny of the Dactylopius introduced from Hawaii were transported to Santa Cruz by Stanton. Crawlers hatched en route. One or two infested pads apiece were placed in cactus clumps covered with DDT-treated mosquito netting. The netting subsequently was secured at the edges with dirt, and a 6-inch-wide band of Dieldrin was dusted around each clump. The insecticide protected these colonies from attack by ants and coccinellid predators. These colonizations probably occured just west of the ranch headquarters (fig. 2). Smith retired from the University the following July, and no further introductions of 


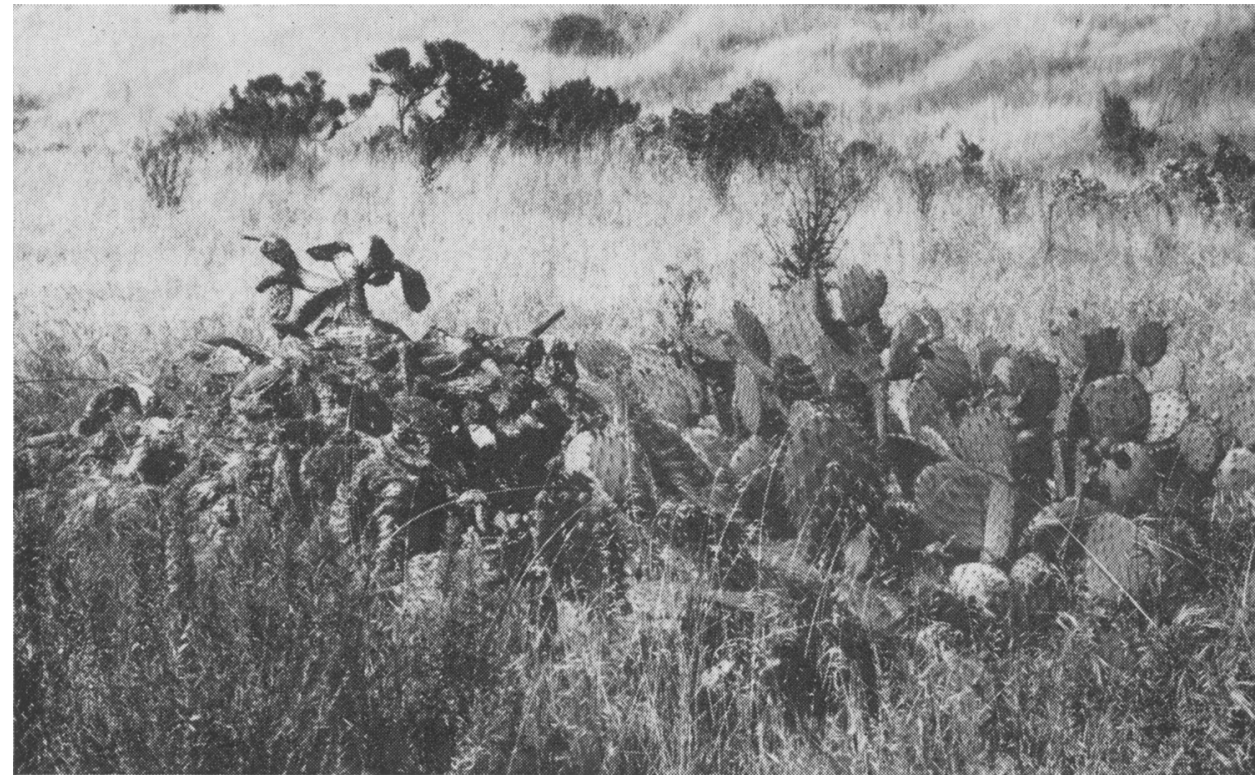

Fig. 10. Opuntia littoralis (left) and O. oricola (right), on Santa Cruz Island, following attack by Dactylopius sp. Note that $O$. oricola is apparently more resistant. (May 4, 1966.)

the cochineal insects were undertaken.

Mr. M. E. Cravens, Deputy Agricultural Commissioner of Santa Barbara County, California, provided the first evidence of the establishment of the Dactylopius from Hawaii on Santa Cruz Island. In November, 1955, Cravens observed, described, and photographed Dactylopius-infested cacti located just west of the ranch headquarters, probably not far from the original colonization site. Cravens also undertook the first redistribution of cochineal-infested pads at this time, and several pads each were placed within cactus clumps at many unrecorded locations in the western portion of the central valley.

After visiting the island in mid-1958, Holloway suggested to Dr. Carey Stanton, Edwin Stanton's son and the present owner of the Stanton Ranch, that additional distribution be effected. Subsequently, during 1959 and 1960, several jeeploads of Dactylopius-infested pads were widely distributed on the island by Cravens, Holloway, Fleschner, and Stanton Ranch personnel. During late May, 1960, Mr. Pier Gherini, coowner of the Gherini Ranch, which occupies the extreme eastern end of Santa Cruz Island, successfully colonized Dactylopius sp. at his end of the island by placing approximately 12 heavily infested pads within cactus clumps at each of two locations (Cravens, personal communication).

Results. Since 1951, Dactylopius sp. has increased slowly but steadily in numbers and has destroyed considerable prickly pear cacti on Santa Cruz Island. These processes continue to the present date.

Observations from 1961 to 1966 indicated that Dactylopius sp. had spread throughout the island. It was observed at all sampling sites during the May 13 to 16,1966 , survey (fig. 3 ).

Dactylopius sp. was spread mechanically as noted above. Natural distribution presumably occurred via windborne crawlers (Dodd, 1940). In overgrazed, sheep-infested areas, the animals were observed to force their way beneath opuntia clumps in search of grass or shelter. As the sheep emerged 
from these clumps, Dactylopius-infested pads became matted in the shaggy fleece. The pads subsequently were jostled free, to land in contact with uninfested clumps and to inoculate them with Dactylopius sp. (Cravens, personal communication).

Beginning in 1961, sequential photographs were taken biannually of selected clumps of prickly pear cacti to provide evidence of cactus mortality induced by Dactylopius sp. The locations of these photographic sites are given in figure 3 . Specimens of both $O$. oricola and $O$. littoralis, as well as their hybrids, were photographed. Their identity was confirmed in the field by Dr. R. A. Philbrick, Botanist, Santa Barbara Botanic Garden, Inc. The photographs were taken during the spring and fall, at similar times of the day, at the same photographic sites. To assure the visual continuity of each photographic series, the composition of each initial photograph was matched during subsequent photography.

The choice of cactus clumps to be photographed was governed largely by the specimens available in proximity to the jeep trails that lace the island's rugged terrain, and the locations of the specimens relative to other sample sites. The presence of Dactylopius sp. was confirmed at each site, but, of course, the rapid reproduction of the insects and a marked deterioration of the cacti could not be assured.

The results of Dactylopius sp. attack are shown in plates 1 to 4 . Differential rates of clump deterioration were observed. Apparently, $\boldsymbol{O}$. littoralis and $\boldsymbol{O}$. littoralis $\times \boldsymbol{O}$. oricola hybrids that resemble the former species are more susceptible to Dactylopius attack than is $O$. oricola. This phenomenon is well illus- trated by figure 10 , showing a clump of $O$. littoralis and a clump of $O$. oricola which grew in juxtaposition. The $O$. littoralis had been killed by Dactylopius sp. attack, whereas the $O$. oricola had not as yet succumbed. Dactylopius sp. definitely attacks $\boldsymbol{O}$. oricola and its hybrids; however, $O$. littoralis is by far the preferred host.

The current persistence of annual grasses on formerly overgrazed and essentially denuded grazing lands is due largely to sheep eradication measures plus restrained cattle grazing (plates 2 and 4). Several species of range grasses, including Avena fatua Linnaeus and Bromus rigidus Roth, ${ }^{6}$ occur on these lands and have invaded areas formerly occupied by cacti. The conservation of this grass cover by restricted grazing has substantially curbed the spread of Opuntia spp. Fallen pads held aloft by the grasses cannot take root, and vegetative propagation is curtailed. During the late winter and the spring growth periods, these grasses also compete directly with cacti for water and nutrients. Cacti not weakened by insect damage are formidable rangeland competitors (Wilson, 1953) ; however, Dactylopius injury undoubtedly has reduced the competitive advantage of the cacti in favor of these pioneer grasses.

Dactylopius sp. thus is considered to be the prime biological control agent now operative on Santa Cruz Island. Control of $\boldsymbol{O}$. littoralis and the $O$. littoralis $\times$ O. oricola hybrids, which resemble the former species, is best assessed as "substantial." Partial control of $O$. oricola and hybrids near this species has also been effected.

Natural enemies ${ }^{7}$ of Dactylopius sp. That a phytophagous insect imported

\footnotetext{
${ }^{5}$ Determined by R. A. Philbrick, Santa Barbara Botanic Garden, Inc.

${ }^{6}$ Determined by O. F. Clarke, Department of Life Sciences, University of California, Riverside.

${ }^{7}$ Credits for determination of some of the insects mentioned in this section are as follows: Sympherobius barberi by P. A. Adams and O. S. Flint; S. bifasciatus by O. S. Flint; Eremochrysa punctinervis by P. A. Adams; Leucopis n. sp. by J. F. McAlpine; Aegilips sp., Pachyneuron mucronatum, and Spilochalcis flavopicta by B. D. Burks; Pachyneuron eros, Hippodamia convergens, $H$. quinquefasciata punctulata, Hyperaspis taeniata significanus, and Homalotylus affinis by P. H. Timberlake; Laetilia coccidivora by W. D. Duckworth.
} 


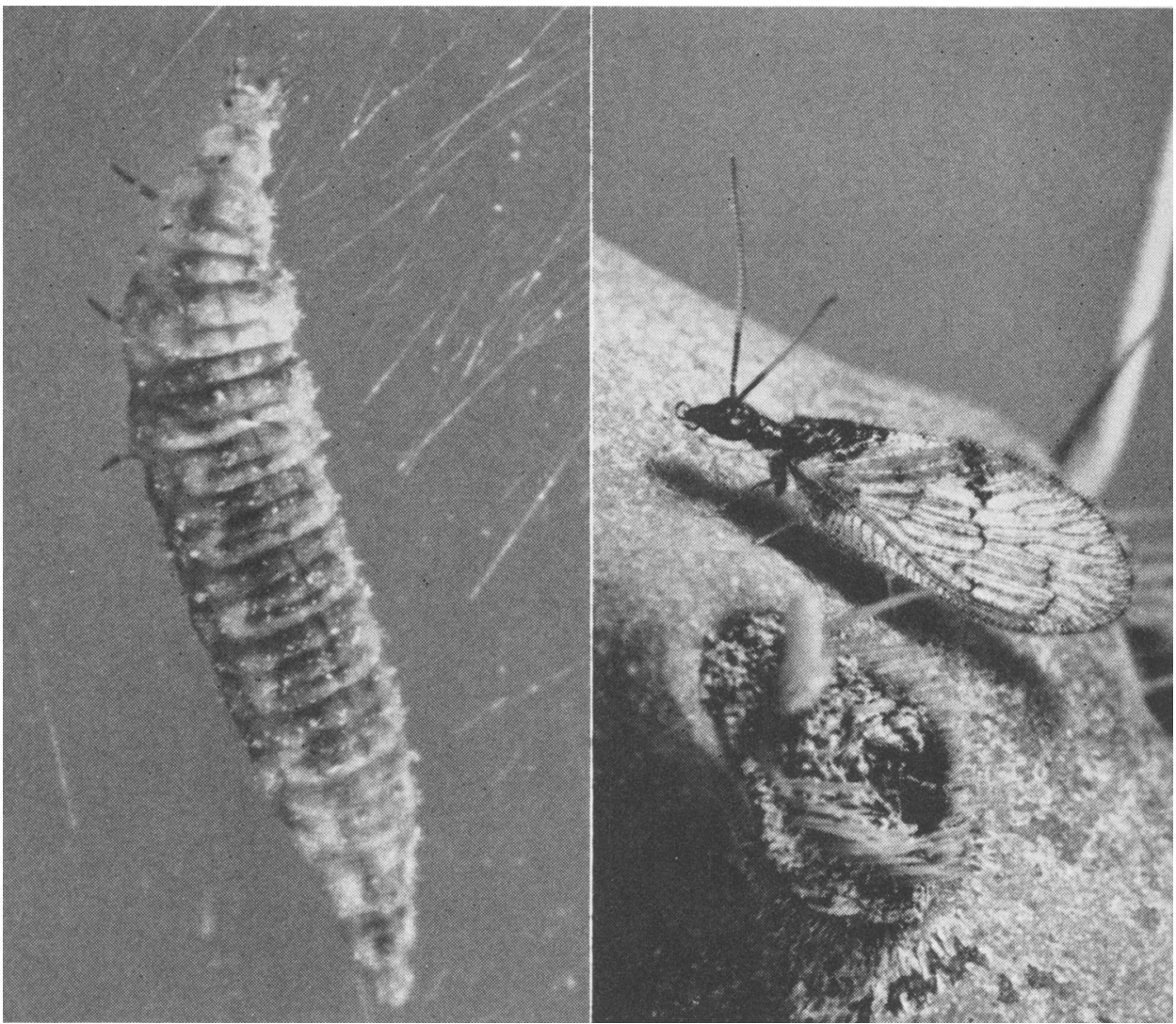

Fig. 11. Sympherobius barberi. Left: larva; right: adult.

for weed control should be free of its natural enemies is a basic principle of biological weed control (Wilson, 1949; Huffaker, 1957). The depredations of natural enemies of cochineal insects were early recognized by Hunter, Pratt, and Mitchell (1912), who at the time viewed cacti as innoxious, and cactusfeeding insects as noxious, and by the Australian Prickly-Pear Traveling Commission, who anticipated the use of these insects in biological control: "These wild cochineal insects are evidently controlled to a great extent by various predators and parasites and therefore the Commission did not see the full destruction that they might cause had these controlling aspects been absent." (Johnston and Tryon, 1914.)

Consequently, this principle dictated that cochineal insects be introduced to Santa Cruz Island free of their mainland-occurring natural enemies. Once established on the island and protected from their natural enemies by the spatial barrier of the Santa Barbara Channel, these insects could freely multiply, concomitantly damaging their cactus hosts within the limits imposed by the remaining biotic factors and the abiotic factors that constituted the Channel Island environment.

The principal components of the natural-enemy complex associated with Dactylopius spp. on the southern California mainland have been defined. The natural enemies of the cochineal insect that was colonized on Santa Cruz Island were identified, as were the natural enemies of Dactylopius spp. collected at 
mainland locations at a latitude similar to that of Santa Cruz Island. These insect enemies were reared from insectary cagings of field-collected, Dactylopius-infested cactus pads unless otherwise noted.

Several lacewings are predators of southern California cochineal insects. Sympherobius barberi (Banks) (Neuroptera: Hemerobiidae) (fig. 11) is by far the most common species, and was easily reared from infested pads collected both on Santa Cruz Island and at various locations on the California mainland. Only a single specimen of $S$. bifasciatus Banks was taken in mainland collections. A few specimens of the common western species, Eremochrysa punctinervis M'Lachlan (Neuroptera: Chrysopidae), were also reared from Dactylopius-infested pads collected on Santa Cruz Island.

The predaceous larvae whose adults were identified as Leucopis n. sp. (Diptera: Chamaemyiidae) (fig. 12) were also commonly associated with Dactylopius spp., both on the California mainland and on Santa Cruz Island. Three species of parasites were reared from puparia of Leucopis n. sp. isolated from mainland collections: Aegilips sp. possibly clarimontis Kiefer (Hymenoptera: Figitidae); Pachyneuron mucronatum Girault (Hymenoptera: Pteromalidae); and P. eros Girault. The latter species was also reared from Leucopis n. sp. puparia isolated from Santa Cruz Island collections.

Two species of predaceous Coccinellidae were collected as adults on Santa Cruz from cactus pads infested with Dactylopius sp.: Hippodamia convergens Guerin-Meneville and $H$. quinquefasciata punctulata LeConte. Both species are also common to the California mainland (Essig, 1926).

Two predaceous species, however, were commonly encountered in mainland collections, yet were conspicuously absent from Santa Cruz Island: Hyperaspis taeniata significanus Casey (Co- leoptera: Coccinellidae) (fig. 13) and Laetilia coccidivora (Comstock) (Lepidoptera: Phycitidae) (fig. 14). Both species were reared from pads infested with the same species of Dactylopius as that introduced to Santa Cruz Island. The distribution of $L$. coccidovora in southern California apparently coincides closely with that of its cochineal host. The larvae of $H$. taeniata signifcanus were parasitized by Homalotylus affinis Timberlake (Hymenoptera: Encyrtidae). Spilochalcis flavopicta (Cresson) (Hymenoptera: Chalcididae) was reared from Dactylopius colonies infested with $L$. coccidivora larvae; however, its host was not positively identified. Burks (personal communication) noted that this species should be a primary or secondary parasite of Lepidoptera.

Despite all precautions, the Santa Barbara Channel was bridged by several species of predators. These insects probably had invaded the island, unaided, at an early date, although their inadvertent introduction during the course of these studies cannot be positively ruled out. Interestingly, the exclusion from Santa Cruz Island of but two species of predators, $L$. coccidivora and $H$. taeniata significanus, both of which are significant mainland predators of Dactylopius sp., apparently has facilitated the rise of the cochineal population density to its present destructive level.

All insect enemies of Dactylopius spp. apparently are predators. Aside from the speculative allusion to "parasites" of cochineal insects by Johnston and Tryon (1914), we have found only one parasite record. Formicencyrtus thoreauini Girault was described (Girault, 1916) ". . . from two females on tags in the U.S.N.M. collections. . . On coccus [sic] confusus. Mesilla Park, New Mexico. Cockerell. Emerged December 14, 1896. . . ." Muesebeck, Krombein, and Townes (1951) and Thompson (1944) list $F$. thoreauini as a parasite of Dacty- 

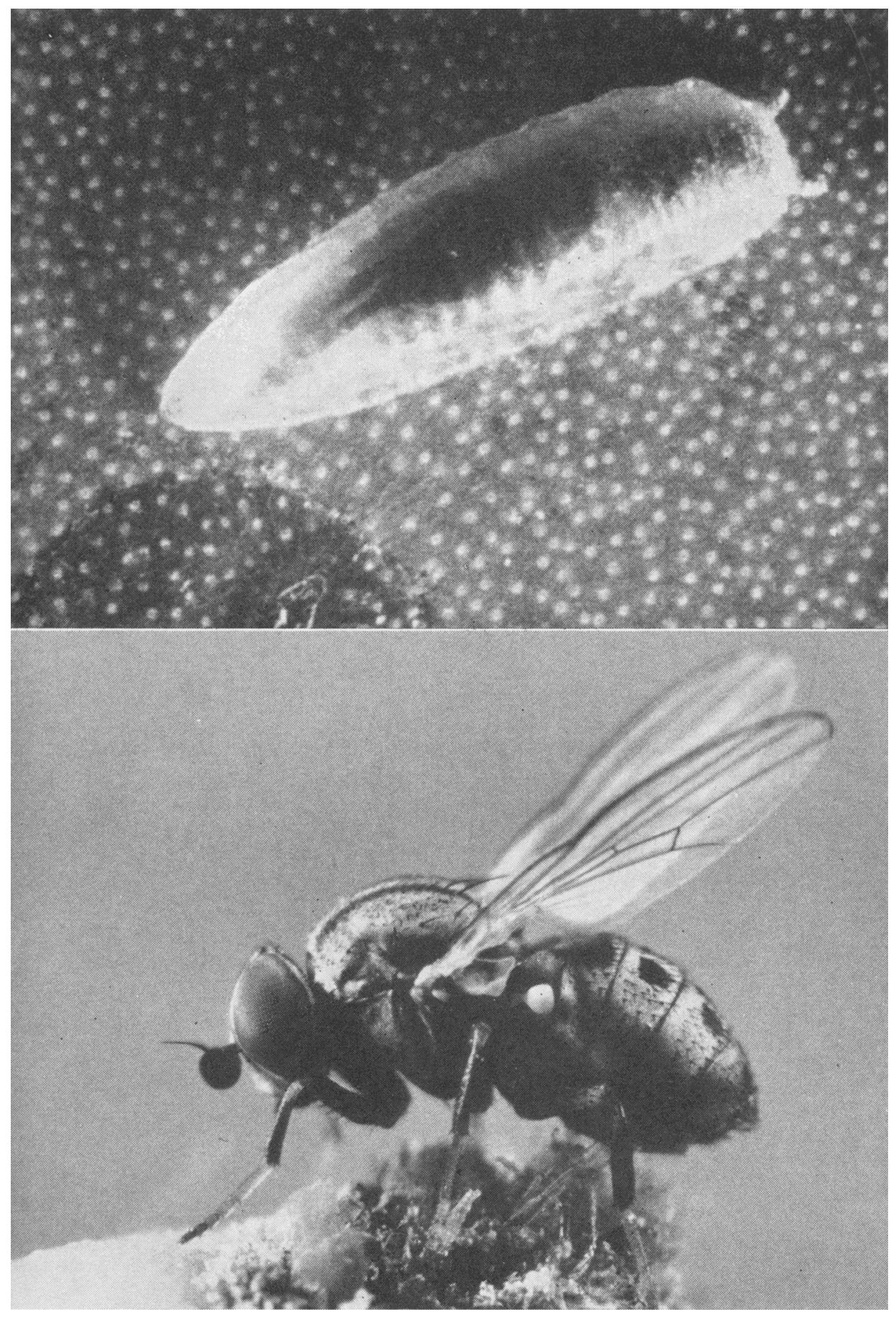

Fig. 12. Leucopis n. sp. Top: larva; bottom: adult. 

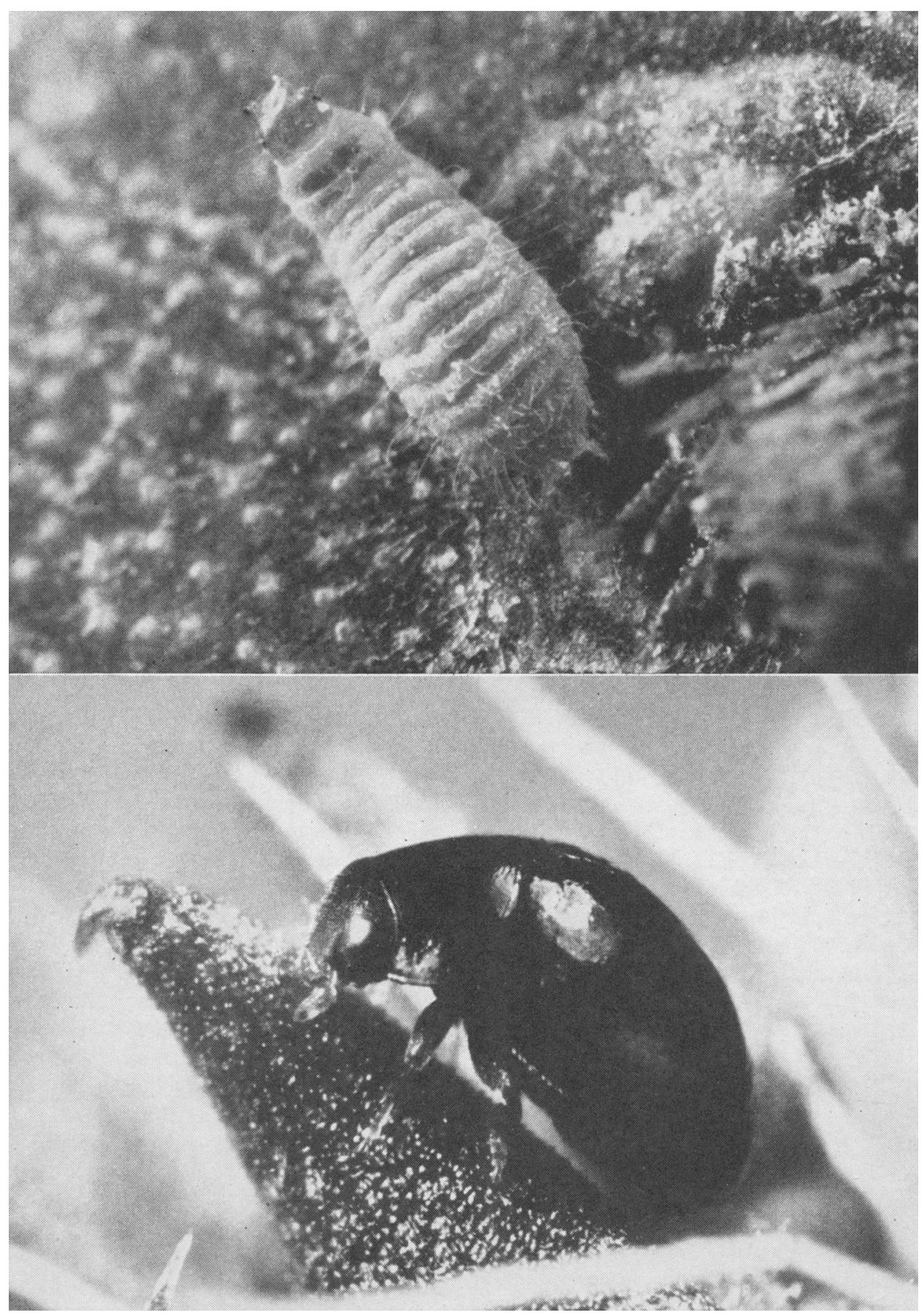

Fig. 13. Hyperaspis taeniata significanus. Top: larva; bottom: adult. 


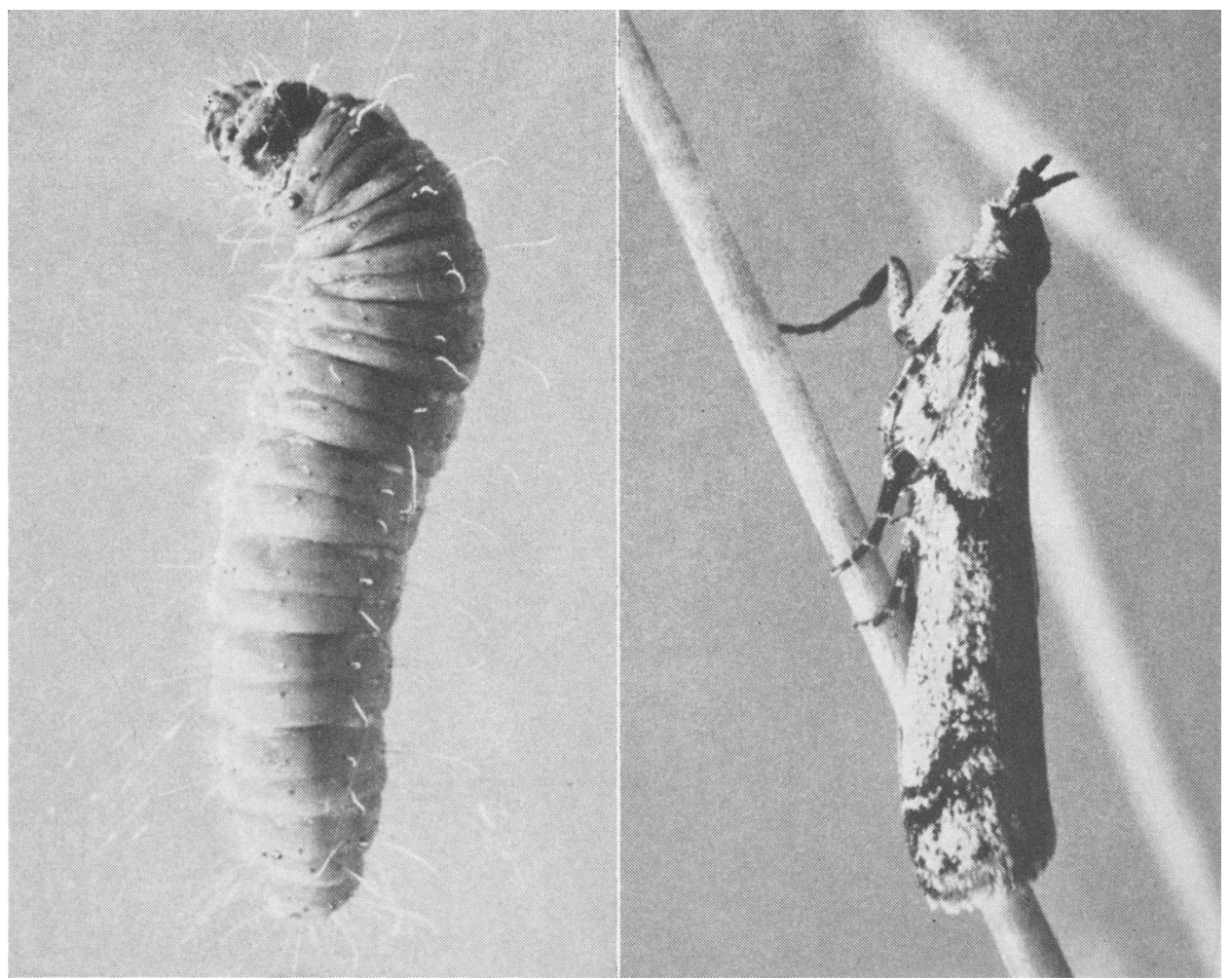

Fig. 14. Laetilia coccidivora. Left : larva; right: adult.

lopius spp., and both cite only Girault (1916). The reviews of Hunter, Pratt, and Mitchell (1912), Alexander (1925), and Dodd (1940) listed only predators of Dactylopius spp. Furthermore, the cochineal predators, Saluria ardiferella Hulst and Hyperaspis cruenta LeConte, were recorded from Mesilla Park, New Mexico (Hunter, Pratt, and Mitchell, 1912), and it is likely that one of these species or some other insect associate of $D$. confusus was the true host of $F$. thoreauini.

Smith was well aware of the fact that Dactylopius spp. lacked parasitic natural enemies. On August 14, 1944, in a letter to an entomologist who had sent him specimens of an insect presumed to be parasitic on Dactylopius, Smith replied:

When I received your letter of August 10 stating you had reared a parasite from the cactus mealy bug [sic] I was very much surprised and elated, because I have been looking for such a parasite for a good many years and have handled hundreds of thousands of mealy bugs [sic] and had not succeeded.

When I received the specimens, however, I was disappointed because they are a species of Pachyneuron, which supposedly had developed on the little fly Leucopis, a common predator on this mealy bug $[$ sic $]$.

We too have failed to discover a parasite of Dactylopius spp. Parasites assuredly were reared, but in all but one instance, as noted above, they were positively identified as parasites of predaceous species that infested the cochineal colonies. 


\section{DISCUSSION}

The partial to substantial control of opuntia spp. attained to date on Santa Cruz Island lends additional credence to arguments for the continued and expanded employment of the biological method of weed control (Wilson, 1949, 1964; Huffaker, 1957, 1964; Holloway, 1964). Not only has the efficacy of the method again been demonstrated, but several observations of ecological note relative to entomophagous insect: phytophagous insect: host-plant interrelationships have also been reported.

The capacity of phytophagous insects to regulate the abundance of their plant hosts was demonstrated by the cochineal-induced destruction of cacti on Santa Cruz Island. Wilson $(1949,1964)$ and Huffaker (1957, 1959) discussed the role of insects in plant ecology and cited several instances (notably past successes in biological weed control, but also excerpts from the general ecological literature) wherein natural enemies were reported to regulate plant abundance and plant community composition. These workers also reviewed and debated the reasons for the greater abundance shown by some introduced weeds in alien environments. Wilson (1964) rightly questioned the marked tendency for such discussion to center on the physical environment and thus tend to minimize the role of recognized biotic influences, including natural enemies, currently the stock in trade of biological weed control:

In a situation in which one can point to many possible biotic factors (differences in natural enemies, plant competitors, grazing, farming practices, etc.) to account for greater importance of a weed in a new country, it is unjustifiable, without sound, demonstrable reason, to assume a more favorable physical environment.
The similarity of abiotic influences on Opuntia oricola, $O$. littoralis, and Dactylopius sp. inhabiting both Santa Cruz Island and the adjacent southern California coastal mainland affords us a unique opportunity to isolate and assess the importance of biotic factors, taken as a whole, in determining the abundance of the introduced cacti and cochineal insects. Both coastal mainland and adopted island habitats have essentially the same macroclimate (a physical factor given the most attention as a determinant of alien organism abundance by Wilson and Huffaker). Furthermore, the edaphic (nutritional adequacy, $\mathrm{pH}$, structure, texture of the soil substrate) and topographical (slope, exposure) requirements of $O$. oricola and $O$. littoralis certainly are satisfied in both locales. To an appreciable degree, then, relative differences in cactus and cochineal densities mirrored dissimilarities of biotic influences in coastal mainland and insular southern California.

Prior to the introduction of Dactylopius sp., the cacti inhabited two geographically isolated areas in southern California which share essentially the same abiotic environment. On Santa Cruz Island, however, removal of plant competition by overgrazing, plus freedom from deleterious insects, promoted cactus densities of pest proportions, whereas, along the California coast these same cacti are of "much lower density" (R. N. Philbrick, personal communication) within their natural ranges on south-facing slopes to elevations of 500 feet.

Huffaker (1957) emphasized that the greater favorability of the adopted environment might also enhance the chances for weed control by an introduced phytophagous insect. Thus, the previous conjecture concerning the causes of differences in the population densities of island- and mainland-in- 
habiting prickly pear cacti can be extended to an assessment of the relative densities of mainland and island Dactylopius sp. populations. The exclusion of important constituents of the mainland predator complex of Dactylopius sp. from Santa Cruz Island apparently has promoted a rise in the population density of the introduced cochineal insects to their present destructive level. Significantly, field observation indicated that natural stands of $\boldsymbol{O}$. oricola and $\boldsymbol{O}$. littoralis along the coast of lower southern California support far fewer colo- nies of Dactylopius sp., and that these colonies invariably show evidence of considerable predator activity.

In summary, we believe that the considerable measure of biological control of prickly pear cacti now evidenced on Santa Cruz Island is largely a result of the manipulation of certain biotic factors: primarily, the introduction of a destructive natural enemy; secondarily, the initiation of better range management (a regeneration of plant competition through sheep and boar eradication and restricted grazing.

\section{ACKNOWLEDGMENTS}

The collective assistance of the plant and insect systematists who identified the many species involved in this study is gratefully acknowledged. Special thanks are due Dr. Carey Stanton for his hospitality during our periodic visits to Santa Cruz Island, for his continuing interest in our efforts, and for providing us with copies of his father's correspondence; Mr. M. E. Cravens, Deputy Agricultural Commissioner, Santa Barbara County, for his active participation and interest in these studies, for providing copies of pertinent correspondence, and for verbal and written comment on the progress of cactus control on the island; Dr. W. H. Anderson, Chief, Insect Identification and Parasite
Introduction Research Branch, Entomology Research Division, Agricultural Research Service, U. S. Department of Agriculture, for facilitating the identification of our insect specimens; Dr. R. N. Philbrick, Santa Barbara Botanic Garden, Inc., for his interpretive analyses of Opuntia spp. destruction on the island. Permission to use U. S. Department of Agriculture correspondence files is also gratefully appreciated. Thanks are also due Drs. C. P. Clausen, S. E. Flanders, and J. A. McMurtry for constructive review of the manuscript. Photographs in figss. 5 to 9 and 11 to 14 were taken by K. L. Middleham, University of California, Riverside. 


\section{LITERATURE CITED}

Alexander, W. B.

1925. Natural enemies of prickly pear and their introduction into Australia. Commonwealth Australia Inst. Sci. Ind. Bul. 29. 80 pp.

Bremner, C. ST. J.

1932. Geology of Santa Cruz Island, Santa Barbara County, California. Santa Barbara Mus. Nat. Hist. Occasional Papers No. 1. 33 pp.

BugBeE, R. E., and A. REIGEL

1945. The cactus moth, Melitara dentata (Grote), and its effect on Opuntia macrorrhiza in western Kansas. Amer. Midland Nat. 33 : 117-27.

Dopd, A. P.

1940. The biological campaign against prickly pear. Commonwealth Prickly-Pear Board, BrisEssig, E. O. bane, Australia. 177 pp.

1926. Insects of western North America. New York: The MacMillan Co. $1035 \mathrm{pp}$.

Ferris, G. F.

1955. Atlas of the scale insects of North America. Vol. VII. The families Aclerididae, Asterolecaniidae, Conchaspididae, Dactylopiidae, and Lacciferidae. Stanford, Calif.: Stanford Univ. Press. $233 \mathrm{pp}$.

Fullaway, D. T.

1954. Biological control of cactus in Hawaii. Jour. Econ. Ent. 47 : 696-700.

Girault, A. A.

1916. New Encyrtidae from North America. Psyche 23: 41-50.

HAMLin, J. C.

1924. A review of the genus Chelinidea (Hemiptera-Heteroptera) with biological data. Ann. Ent. Soc. Amer. 17: 193-208.

1925. Important Opuntia insects of the United States, biological notes on the moth borers (Pyralidae). Pan-Pac. Ent. 2: 1-11.

HEINRICH, C.

1939. The cactus-feeding Phycitinae: a contribution toward a revision of the American pyralidoid moths of the family Phycitidae. Proc. U. S. Natl. Mus. 86 : 331-413.

HILLINGER, C.

1958. The California islands. Los Angeles, Calif.: Academy Publications. 165 pp.

Holloway, J. K.

1964. Projects in biological control of weeds. In: Biological control of insects pests and weeds (P. DeBach, ed.). New York: Reinhold Publishing Corp. pp. 650-69.

Holloway, J. K., and C. B. HuFFakeR

1949. Klamath weed beetles. Calif. Agr. 3(2): 3, 10.

HUFFAKER, C. B.

1957. Fundamentals of biological control of weeds. Hilgardia $27(3): 101-57$.

1959. Biological control of weeds with insects. Ann. Rev. Ent. 4: 251-76.

1964. Fundamentals of biological weed control. In: Biological control of insect pests and weeds (P. DeBach, ed.). New York: Reinhold Publishing Corp. pp. 631-49.

Hunter, W. D., F. C. Pratt, and J. D. Mitchell

1912. The principal cactus insects of the United States. U. S. Dept. Agr. Bur. Ent. Bul. 113. $71 \mathrm{pp}$.

Johnston, T. H., and H. TRYoN

1914. Report of the Prickly-Pear Travelling Commission, Nov. 1912-Apr. 1914. Brisbane, Australia. $131 \mathrm{pp}$.

Muesebeck, C. F. W., K. V. Krombein, and H. K. Townes

1951. Hymenoptera of America north of Mexico. Synoptic Catalogue. U. S. Dept. Agr., Agr. Monogr. No. 2. 1420 pp.

Munz, P. A., and D. D. KECK

1959. A California flora. Berkeley and Los Angeles: University of California Press. 1681 pp. PhILBRICK, R. N.

1964. Opuntia oricola, a new Pacfic Coast species. Cactus \& Succulent Jour. Amer. 36: 163-65. SмITH, H. S.

1947. Biological control of weeds in the United States. Proc. Ent. Soc. Washington 49: 169-70. 
STONE, A. (ed.)

1964. California information almanac. Lakewood, Calif.: California Information Almanac Co., Inc. $521 \mathrm{pp}$.

Thompson, W. R.

1944. A catalogue of the parasites and predators of insect pests. Sec. 1, Part 3. Imp. Agr. Bur. Inst. Ent., Imp. Parasite Serv., Belleville, Ontario, Canada. 149 pp.

WILsON, F.

1949. The entomological control of weeds. Un. Int. Sci. Biol. (B) 5: 53-64.

1953. Some aspects of the control of weeds by insects. Proc. 7th Pac. Sci. Cong. 4: 294-99.

1960. A review of the biological control of insects and weeds in Australia and Australian New Guinea. Commonwealth Inst. Biol. Control Tech. Comm. No. 1. 102 pp.

1964. The biological control of weeds. Ann. Rev. Ent. 9: 225-44. 
The journal HILGARDIA is published at irregular intervals, in volumes of about 650 to 700 pages. The number of issues per volume varies.

Single copies of any issue may be obtained free, as long as the supply lasts; please request by volume and issue number from:

$$
\begin{aligned}
& \text { Agricultural Publications } \\
& \text { University Hall } \\
& \text { University of California } \\
& \text { Berkeley, California } \mathbf{9 4 7 2 0}
\end{aligned}
$$

The limit to nonresidents of California is 10 separate titles. The limit to California residents is 20 separate titles.

The journal will be sent regularly to libraries, schools, or institutions in one of the following ways:

1. In exchange for similar published material on research.

2. As a gift to qualified repository libraries only.

3. On a subscription basis- $\$ 7.50$ a year paid in advance. All subscriptions will be started with the first number issued during a calendar year. Subscribers starting during any given year will be sent back numbers to the first of that year and will be billed for the ensuing year the following January. Make checks or money orders pay. able to The Regents of The University of California; send payment with order to Agricultural Publications at above address. 